\title{
Risk Choices and Compensation Design
}

Carey, Mark and Bo Sun
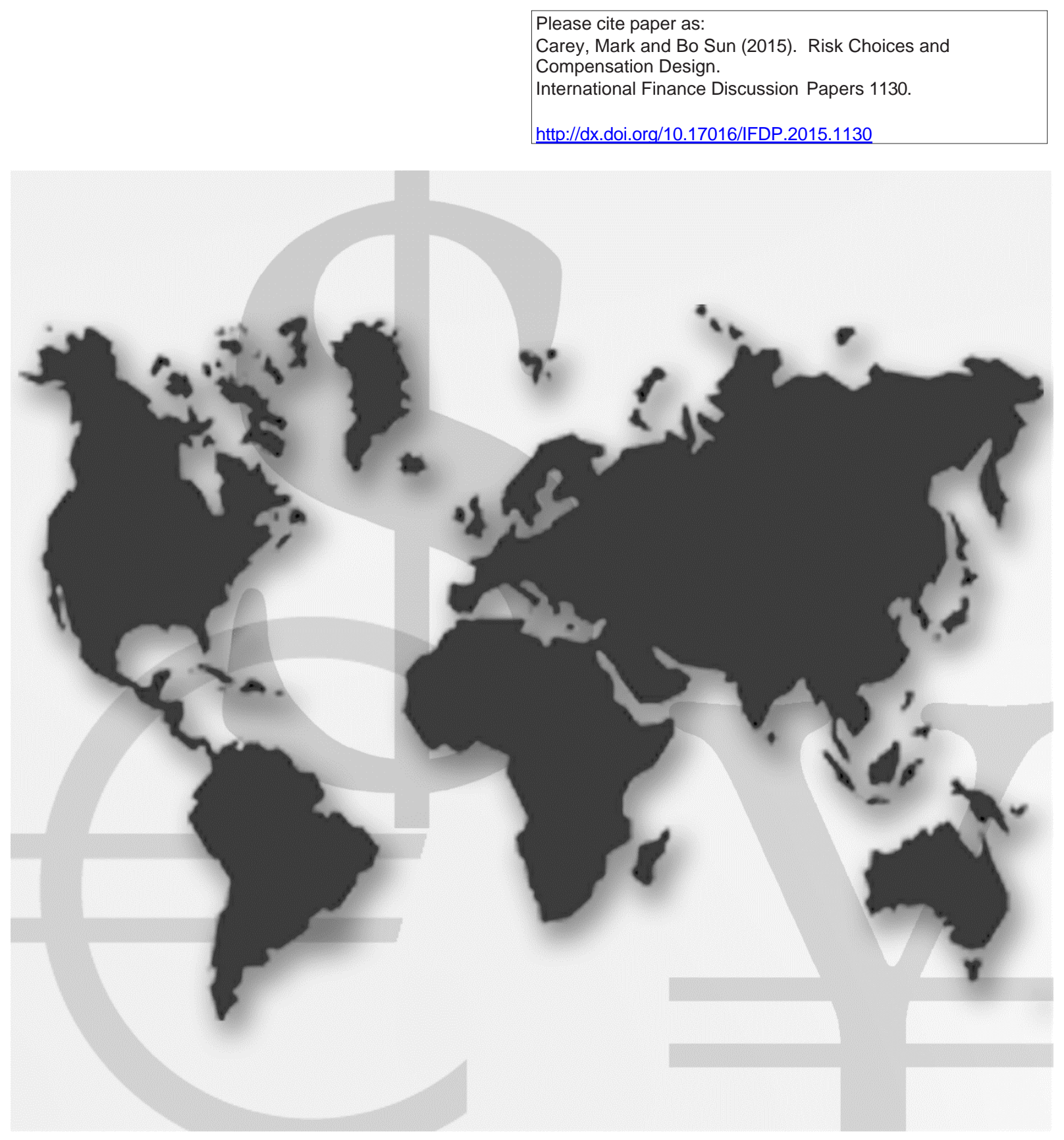

\section{International Finance Discussion Papers}

Board of Governors of the Federal Reserve System

Number 1130

January 2015 


\section{Board of Governors of the Federal Reserve System \\ International Finance Discussion Papers}

Number 1130

January 2015

\section{Risk Choices and Compensation Design}

Mark Carey and Bo Sun

NOTE: International Finance Discussion Papers are preliminary materials circulated to stimulate discussion and critical comment. References to International Finance Discussion Papers (other than an acknowledgment that the writer has had access to unpublished material) should be cleared with the author or authors. Recent IFDPs are available on the Web at www.federalreserve.gov/pubs/ifdp/. This paper can be downloaded without charge from the Social Science Research Network electronic library at www.ssrn.com. 


\title{
Risk Choices and Compensation Design
}

\author{
Mark Carey and Bo Sun
}

\begin{abstract}
:
We analyze the impact of bad-tail risks on managerial pay functions, especially the decision to pay managers in stock or in options. In contrast to conventional wisdom, we find that options are often a superior vehicle for limiting managerial incentives to take bad-tail risks while providing incentives to exert effort. Arrangements similar to collar options are able to incent the desired project choice in wider range of circumstances than call options or stock. However, information requirements appear high. We briefly explore alternatives with features similar to maluses and clawbacks, which are a bit like weakening the limited liability of managers.
\end{abstract}

Keywords: Compensation, Bad tail risk

JEL classifications: G34, D86, G20

The authors are staff economist in the Division of International Finance, Board of Governors of the Federal Reserve System, Washington, D.C. 20551 U.S.A. The views in this paper are solely the responsibility of the authors and should not be interpreted as reflecting the views of the Board of Governors of the Federal Reserve System or of any other person associated with the Federal Reserve System. 


\section{Introduction}

Compensation practices that incentivized excessive risk-taking at financial institutions has often been mentioned as one factor contributing to the recent financial crisis. ${ }^{1}$ A typical story is that compensation packages rewarded managers for projects that generated high returns in most states of the world but that also had a small perceived probability of very large losses (bad tail risk). Empirical evidence on the role of compensation in the crisis is mixed, though extant empirical studies do not focus on bad tail risk (e.g., Fahlenbrach and Stulz (2011); DeYoung, Peng and Yan (2013); Shue and Townsend (2013)). Moreover, it is not clear that boards of directors of large financial services firms intentionally provided incentives to take bad tail risk: They compensated executives much more in stock than in options before the crisis, and conventional wisdom had been that stock incents less risk-taking than options. ${ }^{2}$ Boards also may have been inattentive to risk-taking incentives: There is little evidence, either anecdotal or in texts of proxy statements, that risk was a primary focus or expertise of financial institutions' compensation committees. ${ }^{3}$

We presume that boards of directors now wish to limit incentives to take inefficient badtail risk. We investigate the ability of pay functions that resemble stock and options to incentivize managers to exert effort while avoiding bad-tail risk, making three main contributions. First, we find that pay functions similar to options are more effective in deterring tail risk than those similar to stock for a wide variety of project choice sets. Option-based compensation permits shareholders to establish floor and cap values for project payoffs beyond which the manager's compensation is insensitive to the project outcome. Depending on the distributions of project payoffs, the effect of well-designed caps and floors can

\footnotetext{
${ }^{1}$ For example, Rajan (2005), Kashyap, Rajan, and Stein (2008) and Clementi, Cooley, Richardson and Walter (2009).

${ }^{2}$ Smith and Stulz (1985) argue that undiversified managers with high-delta compensation arrangements, such as pay in the form of stock, are likely to take too little risk, while those with high-vega arrangements, such as pay in the form of options, may take too much risk (a sampling of other relevant papers includes Jensen and Meckling 1976, Morck et al. 1988, and John and John 1993).

${ }^{3}$ Though we motivate the paper by reference to financial services firms, it could be relevant to any firm where rewarding effort with pay-for-performance also tends to motivate taking of bad-tail risk.
} 
be to increase the expected value to the manager more for ordinary projects than for tail risk projects, allowing shareholders to incent a value-maximizing choice using options that they cannot achieve using stock-based compensation.

Second, the detail-neutral finding of Edmans and Gabaix (2008) (roughly, shareholders need not have full information to implement the optimal contract) does not hold in our model. Information requirements appear high for robust provision of desired risk-taking incentives when bad-tail risk-taking is a possibility and stock or options are the compensation delivery vehicle. Simulations show that modest changes in the properties of projects can be associated with large changes in the details of the preferred contract. For example, small changes can cause the contract to change to or from any of a call or a put or a collar, and the analog of strike prices can change markedly. We are skeptical that boards possess enough information to enable them to design option contracts that reliably elicit desired behavior. Thus, future research on a wider set of contract forms or risk choice control mechanisms in the presence of tail risk and limited liability would be valuable.

Third, we take a small step toward such research by extending our model to allow pre-existing manager wealth to be forfeited when tail risk outcomes occur, which is similar to weakening the limited liability enjoyed by managers. Real-world examples include clawbacks and maluses, although our setup abstracts from potentially important details of such arrangements. We find that stock-like pay functions are effective in more circumstances if the ex post penalty imposed on the manager when bad-tail realizations occur is sufficiently large. A possible direction for future research is investigation of different ways that firms can cause managerial wealth to be exposed to forfeiture. ${ }^{4},{ }^{5}$

We model contract choice by shareholders wishing to incentivize effort while avoiding bad-tail risk when managers are risk-neutral and enjoy limited liability (though our analysis

\footnotetext{
${ }^{4} \mathrm{~A}$ recent paper with related features is He (2012), which includes the potential for private savings, though the preferred contract protects managerial wealth when performance is poor.

${ }^{5} \mathrm{We}$ also add monitoring of risk choices to our model and find that sufficiently effective and low-cost monitoring can make stock-like contracts optimal. The best monitoring policy is determined by a tradeoff between paying employees a lower wage and the cost of monitoring.
} 
can be extended to include a risk-averse manager, as shown in Appendix D). Our model departs from the standard moral hazard model (Holmstrom 1979) in three ways. First, we include tail risk in the manager's project choice set, that is, a project that may be somewhat more profitable than the ordinary project under normal circumstances but that has NPV smaller than the ordinary project because there exists a small probability of a disastrously low payoff. Thus, shareholders prefer the ordinary project, but they cannot observe the manager's project choice. This is a key modeling choice: If we followed prior literature and focused on project choice sets that are relatively smooth in their characteristics, results would be different. We regard this assumption as improving the realism of the model.

Second, we assume that the manager receives a minimum positive amount of compensation in all states of the world. This captures not only limited liability of the manager and the fixed salary component of compensation, but also the fact, observed during the crisis, that bankers often receive significant positive bonuses even in the wake of disastrous performance. ${ }^{6}$ Third, in most of the paper, we restrict the available contract forms to those resembling stock, call options, put options, or collar options.

We present necessary and sufficient conditions for option compensation to deter tail risk. Collar options, which have both a project payoff floor below which managerial pay is insensitive to outcomes and a cap above which pay is insensitive, are effective if the distribution of tail-risk project payoffs exhibits restricted second order stochastic dominance over the distribution of ordinary project payoffs, with the dominance condition operative over the range between the floor and cap. This result is general for all continuous distributions of project payoffs. ${ }^{7}$ Similarly, call options are effective if the tail risk project exhibits restricted second order dominance for the range of payoffs above the strike (floor).

Figure 1 provides intuition for call options. The manager's compensation (the kinked

\footnotetext{
${ }^{6}$ Though CEOs of many global universal banks ultimately refused any bonus for the 2008 pay year due to public pressure, their boards intended to grant bonuses until pressure was applied, and other employees did receive substantial bonuses, even employees in business units that imposed large losses on their firm.

${ }^{7}$ Davidson and Duclos (2006) show that it is not possible with continuous distributions to empirically reject nondominance in favour of dominance over the entire supports of distributions.
} 


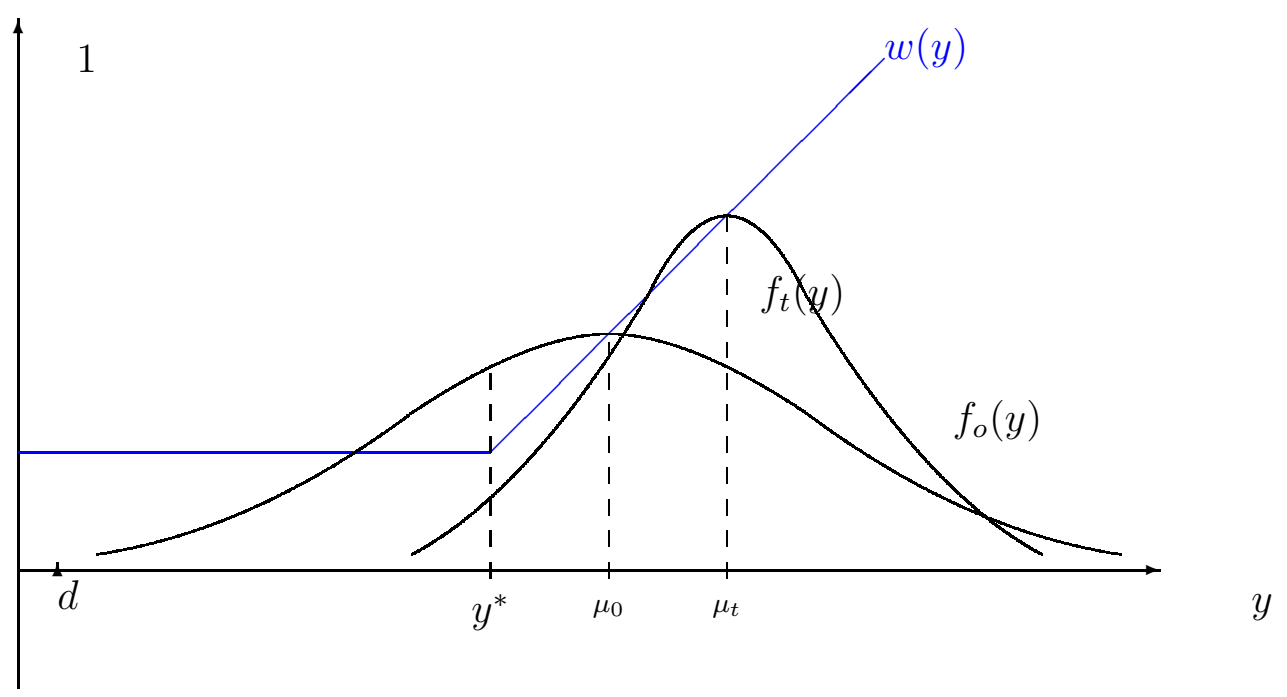

Figure 1: Stocks versus Options

line) varies with the project payoff only for payoffs above the floor $y^{*}$. The ordinary project's payoff distribution has fatter non-disaster tails than the tail risk project's distribution, so the ordinary project has more mass of low returns made irrelevant to the manager by the floor, increasing its expected value to managers relative to the value of the tail risk project. If the properties were reversed, with the tail risk project having fatter tails, an appropriately designed cap (similar to a put option) could accomplish the same thing (if the dominance condition is satisfied). ${ }^{8}$

Because a collar is combination of a put and a call, a call is a special case of a collar (moreover, stock is a special case of a call). A collar offers shareholders more compensation policy levers than calls or stock because shareholders are able to set both a floor and a cap

\footnotetext{
${ }^{8}$ Our results do not require the tail risk project to have relatively thin non-disaster tails, but it seems likely that some tail risk projects do. Many strategies followed by financial services firms that blew up during the crisis did deliver apparent excess returns with low volatility in the years prior to the crisis. Among the examples are: credit-arb ABCP vehicles that provided excess returns with only modest volatility for a number of years until virtually all imposed substantial funding-shock losses on sponsors during the crisis; highly rated securitized mortgage bonds; credit protection sold by monoline insurance companies on such bonds and on bank debt; and quant equity strategies used by some hedge funds to obtain high Sharpe ratios for many years until large losses were experienced in the fall of 2007.
} 
as well as the slope of the compensation function between the floor and cap. This increases the set of circumstances in which shareholders can incentivize both high effort and no tail risk. To the best of our knowledge, our paper is the first to point out the benefits of collars in compensation design.

Compensation arrangements must incentivize effort as well as the desired level of risk taking. We use a trade-off between avoiding tail risk and inducing managerial effort to determine equilibrium floors and caps and the optimal proportion of firm value granted in equity or in option compensation. When collars are used, the same insensitivity of managerial payoffs to outcomes below (above) the floor (cap) that has an impact on risk incentives also makes payoffs less sensitive to effort. To induce effort, the manager must be given a stronger pay-for-performance incentive (a larger share of the firm) between the floor and cap relative to that required with stock-based compensation.

We do not model the optimal contract because we model project choices and payoffs with a richness that would make the model too complicated if we did not restrict the set of allowable contracts. A common strategy in optimal-contract modeling is to specify a discrete state space with a limited number of states, but such a strategy would too severely limit our ability to characterize ordinary and tail risks. Instead we restrict the set of allowable contracts to those resembling stock and options. As described further below, given that information requirements for even a limited set of contracts appear high, we are skeptical that contracts with even more nonlinearity would be practical.

The extant theoretical literature on compensation is large. Our paper is most closely related to Demarzo, Livdan and Tchistyi (2011), who model the optimal contract with risk choice in the presence of limited liability and who find that a feature conceptually related to relaxing limited liability (rewarding survival in a bad state of the world) can be helpful. However, their setting includes only three possible project outcomes, so comparisons of the optimal contract with reality are more stylized than in our setting. The conventional wisdom that options incentivize too much risk has been challenged by Carpenter (2000) 
and Ross (2004), who show the impact depends on the manager's utility function (we assume risk-neutral agents). Our results are also related to literature on risk choices in other contexts. For example, Marshall and Prescott (2001) show that bank regulators can incent desired risk choices of banks by capping the payoff to shareholders in the event that investment returns are high, similar to our finding that caps can be useful. ${ }^{9}$ Edmans and Gabaix (2011) and He (2012) have a different risk environment than ours, and Bolton, Mehran and Shapiro (2011) focus on risk-shifting due to government safety nets. ${ }^{10}$

Our work is also related to the literature on capped bonus plans. Some firms use compensation plans in which the bonus becomes positive after a minimum performance threshold is achieved, then increases with performance, and then remains constant for performance above a cap. Such plans are like the collars we model. A number of papers have suggested drawbacks of using such bonus plans, including earnings management and gaming the reward system (Healy 1985, Murphy 2000, and Jensen 2003). One exception is Arya et al. (2007), which finds that bonus caps can be useful when the CEO's impatience level is unknown to the shareholders. Arnaiz and Salas-Fumas (2008) find that a capped bonus is an optimal way to incentivize effort if distributions have semi-heavy tails. These papers, however, do not consider the possibility that managers can choose the risk profile of their project.

The rest of the paper is organized as follows. Section 2 describes the model setup,

\footnotetext{
${ }^{9}$ Innes (1990) studies financial contracting with limited liability but no risk choice and finds that an optimal contract can be similar to debt.

${ }^{10}$ To mention only a few among many other related theoretical papers, Basak, Pavlova, and Shapiro (2007) show that convexities in compensation arrangements, when combined with manager attitudes toward risk, can induce excessive risk taking. Kadan and Swinkels (2008) show that if nonviability of the firm is not a major issue or is out of managerial control, options always dominate stocks. Diamond (1998) shows that as the cost of effort shrinks relative to payoffs, the optimal compensation arrangement converges to a linear contract. Hemmer et al. (2000) examine restrictions on outcome distributions and utility functions that make a convex component such as stock options an optimal contract. Palomino and Prat (2003) show that when money managers can control the riskiness of the portfolio, they should be paid a fixed sum if performance is above a threshold and zero otherwise. Hellwig (2010) shows that an optimal contract between an entrepreneur and a financier may always involve excessive risk taking, depending on the entrepreneur's initial wealth.
} 
and Section 3 shows that stock compensation can incent effort in the absence of risk selection but may cause the manager to choose the tail risk project. Section 4 analyzes the conditions under which collar options and call options incent shareholders' desired risk choice along with high effort. Section 5 reports results of simulations that show that details of the optimal contract are sensitive to changes in project payoff distributions. Section 6 discusses the implications of ex post penalties related to clawbacks; shows that costly monitoring by the principal of the manager's risk choice can substitute for incentives provided by the compensation contract, making stock a useful vehicle in a wider range of circumstances than in the absence of monitoring; and offers remarks about the implications of externalities, especially if the consequences of bad risk outcomes are borne partly by society as a whole, not just by shareholders and managers. The Appendix contains a full characterization of the optimal contract in the context of a simplified binary example, as well as proofs and a description of details of the simulations.

\section{Model}

A risk-neutral principal (shareholders) hires a risk-neutral agent (manager) for one period. The manager chooses a project and the stochastic payoff $y$ is influenced by the manager's effort. ${ }^{11}$

The manager chooses one of two mutually exclusive projects: an ordinary risk project $(o)$ or a tail risk project $(t)$. The payoff when the ordinary risk project is chosen, denoted by $y_{o} \in\left[\underline{y_{o}}, \overline{y_{o}}\right]$, has density $f_{o}(\cdot \mid e)$ and cumulative distribution function $F_{o}(\cdot \mid e)$, where effort $e \in\{l, h\}$. If the manager chooses the tail risk project, with probability $p$, the payoff denoted by $y_{t}^{\prime} \in\left[\underline{y_{t}^{\prime}}, \overline{y_{t}^{\prime}}\right]$ follows a density function $g_{t}(\cdot \mid e)$, where $e \in\{l, h\}$. With probability $(1-p)$, the project leads to a disaster payoff denoted by $d$. We assume that

\footnotetext{
${ }^{11}$ We might also use the term "stock price" for the payoff because of the ubiquity of stock-based bonus plans. However, stocks are a claim on real firms' project cash flows after employee compensation is subtracted. In this paper, "stock price" refers to the project payoff before employee compensation is subtracted.
} 
$d<\min \left\{\underline{y_{o}}, \underline{y_{t}^{\prime}}\right\}$. To avoid carrying $p$ through the notation, we define $y_{t}=p y_{t}^{\prime} \in\left[p \underline{y_{t}^{\prime}}, p \overline{y_{t}^{\prime}}\right]$ to be the stock price excluding the disaster outcome. Therefore, we have $y_{t} \sim f_{t}(y \mid e) \equiv$ $p g_{t}\left(\frac{y_{t}^{\prime}}{p} \mid e\right)$. The cumulative distribution function associated with $f_{t}(\cdot \mid e)$ is $F_{t}(\cdot \mid e)=(1-$ $p) I_{\{y \geq d\}}+\int_{\underline{y_{t}}}^{y} f_{t}(y \mid e) d y$ (including the probability of the disaster). We assume that $f_{o}(\cdot \mid e)$ and $f_{t}(\cdot \mid e)$ are continuous.

The unobserved effort level of the manager, $e$, can take two values, low $(l)$ and high $(h)$, that is, $e \in\{l, h\}$, where $l<h$. The manager incurs disutility $a(e)$ from exerting effort, where high effort has a cost of $a(h)=c$, while low effort involves no cost: $a(l)=0$. High effort by the manager induces a higher expected payoff than low effort. Effort has no impact on the variance of the continuous payoff over the interval $\left[\underline{y_{i}}, \overline{y_{i}}\right], i \in\{o, t\}$, but it does change the expected value of the two projects: It moves the probability distribution function of continuous payoff to the right by a constant amount $\kappa$, regardless of the risk choice. If the manager chooses the tail risk project, the disaster outcome $d$ occurs with probability $(1-p)$ regardless of managerial effort. The payoff is $y_{t} \sim f_{t}(y)$ if the manager exerts high effort and $y_{t} \sim f_{t}(y+\kappa)$ if effort is low. If the manager chooses the ordinary risk project, the distribution of $y_{o}$ conditional on high effort is $f_{o}(y)$, and that conditional on low effort is $f_{o}(y+\kappa)$, where $\kappa>0$. Our results do not depend on the ability of a low-effort manager to control risk.

The manager's compensation is a function of the payoff, $w(y)$. We assume that in all states the manager receives a non-negative minimum wage, denoted by $\underline{w}$, which reflects limited liability of the manager and the observed tendency of firms to pay bonuses even after disastrous performance. Without a minimum wage constraint in the model, the principal could eliminate incentives to take tail risk by imposing sufficiently harsh penalties upon realizations of disasters. ${ }^{12}$

For notational convenience, we denote the expected value of the ordinary risk project given high effort as $\mu_{o}$, that is, $\mu_{o}=\int_{\underline{y_{o}}}^{\overline{y_{o}}} f_{o}(y) d y$. Similarly, the expected value of the

\footnotetext{
${ }^{12}$ Partnership-like arrangements might achieve harsh penalties if partners have sufficient wealth at risk, but in a true partnership there is no separation between managers and shareholders.
} 
tail risk project given high effort when including disaster is $\mu_{t}^{d}=\mu_{t}+(1-p) d$, where $\mu_{t}=\int_{\underline{y_{t}}}^{\overline{y_{t}}} y f_{t}(y) d y .^{13}$ The tail risk project has lower NPV $\left(\mu_{t}^{d}<\mu_{o}\right){ }^{14}$

The net payoff to the principal is the terminal value of the firm less managerial compensation. Prudent risk taking (that is, a choice of the ordinary risk project) induces a higher expected payoff, but it may also induce a higher compensation cost to the principal. We assume that the difference in expected payoff $\left(\mu_{o}-\mu_{t}^{d}\right)$ is large enough that the principal always wants to motivate the manager to take ordinary risk. We also assume that $\kappa$ is large enough that it is always in the best interest of the principal to induce high effort.

The manager maximizes his utility $U(e, y)=w(y)-a(e)$ by choosing an effort $e$ and a project $R \in\{o, t\}$, subject to the contract he is offered. The principal chooses $w(y)$ to minimize the expected labor cost of inducing managerial effort and avoiding tail risk. The optimal contract solves

$$
\min _{w(\cdot)} E\left[w\left(y_{o}\right) \mid h\right]
$$

subject to

$$
\begin{gathered}
h=\underset{e \in\{l, h\}}{\arg \max } E\left[w\left(y_{o}\right)\right]-a(e), \quad \forall y_{o} \sim f_{o}(\cdot \mid e) . \\
E[U(h, y)]=E\left[w\left(y_{o}\right) \mid h\right]-a(h) \geq \bar{U} . \\
w(y) \geq \underline{w}, \quad \forall y . \\
o=\underset{R \in\{o, t\}}{\arg \max } E[U(h, y)]
\end{gathered}
$$

The objective function is the expected cost for the principal to motivate effort and implement the ordinary risk project. The first constraint is the incentive constraint for the manager's choice of effort - as noted previously, we assume that the principal wants to

\footnotetext{
${ }^{13} \mu_{t}=p \int_{\underline{y_{t}^{\prime}}}^{\overline{y_{t}^{\prime}}} y f_{t}^{\prime}(y) d y=\int_{\underline{y_{t}}}^{\overline{y_{t}}} y f_{t}(y) d y$.

${ }^{14} \mathrm{We}$ restrict the project values in this way to make the problem interesting. If the tail risk project had lower expected value even without the disaster outcome, motivating the manager to avoid it would be relatively easy. If the ordinary risk project had lower expected value than the full tail risk project, the principal would prefer the tail risk project. Externalities are discussed in Section 6.3.
} 
induce high effort. The second is the participation constraint, where $\bar{U}$ is the manager's outside option. The third constraint is the minimum wage constraint for the manager.

In general, the participation constraint may not bind, and we restrict our attention to the case where it is always satisfied. Broadly similar results obtain when the participation constraint binds.

In addition to the aforementioned conventional constraints, when the risk choice is not observable, the principal faces another constraint $\left(I C_{R}\right)$ : the manager must make the desired risk choice. Due to the interaction of multiple hidden actions (effort decision and risk choice), compensation off the equilibrium path as well as along the equilibrium path is used to deter joint deviation. Following Doepke and Townsend (2006), we attack this problem by specifying the expected wage that the manager can get when deviating from the recommended risk choice and requiring that in equilibrium it be no larger than the expected wage for the recommended risk choice, regardless of the choice of effort. Two constraints thus must be satisfied:

$$
\begin{array}{ll}
E\left[U\left(h, y_{o}\right)\right] \geq E\left[U\left(h, y_{t}\right)\right], & \left(I C_{R 1}\right) \\
E\left[U\left(h, y_{o}\right)\right] \geq E\left[U\left(l, y_{t}\right)\right] . &
\end{array}
$$

We analyze the case where compensation contracts can take the form of stock or stock options. If a call option is used, $w(y)$ takes the form

$$
w(y)=\underline{w}+\theta \max \left\{y-y^{*}, 0\right\},
$$

where $\underline{w}$ is the minimum wage, $\theta \in[0,1]$ is the proportion of the firm's total payoff received by the manager if the call option is exercised, and $y^{*}$ is the floor above which the manager's pay varies with the project payoff (the strike price or exercise price). If stocks are used, $w(y)$ is expressed as

$$
w(y)=\max \{\underline{w}, \theta y\},
$$

which can be rewritten as

$$
w(y)=\underline{w}+\theta \max \left\{y-\frac{w}{\theta}, 0\right\} .
$$


Note that our definition of stock differs from the conventional definition because of the existence of a minimum wage. ${ }^{15}$ There is an inherent kink at $(\underline{w} / \theta)$ in stock compensation. As the manager is guaranteed $\underline{w}$ in all states, when the payoff falls below $\underline{w} / \theta$, compensation is independent of performance. This captures not only limited liability of the manager, but also the fact, observed during the crisis, that managers received significant positive bonuses even in the wake of disastrous performance.

\section{Stocks versus options: the role of tail risk}

We first examine the choice of effort with no risk choice before developing the full model with project selection. Our goal is to show how the existence of tail risk influences the compensation scheme chosen by the principal. In Section 3.1 we show that stock compensation can be superior to options if only effort matters (because effort can be incentivized at a lower cost with stocks); this is a conventional result. In Section 3.2, we show that stock compensation may actually induce the manager to take tail risk.

\subsection{No project selection or binding minimum wage}

If the ordinary risk project is the only project available, the principal minimizes the expected cost of inducing high effort subject to the minimum wage constraint. Recall that high effort increases the expected payoff of the ordinary risk project by $\kappa$. Incentive compatibility requires the manager to exert high effort if $\left(I C_{e}\right)$ is satisfied, which gives us $\theta \kappa \geq c$. As in the standard principal-agent model, the principal and agent have a conflict of interest over variations in outcomes, and the manager is always in the incentive region of the contract. That is, only stocks are used in efficient contracting. The following lemma, proved in Appendix $\mathrm{C}$, formally states the results in this case.

\footnotetext{
${ }^{15}$ Because the principal can freely choose the exercise value, the minimum wage constraint does not cause a deviation from the conventional form of option compensation. In particular, $w(y)=\max \{\underline{w}, \theta \max \{y-$ $\left.\left.y^{* *}, 0\right\}\right\}$ is equivalent to $w(y)=\underline{w}+\theta \max \left\{y-y^{*}, 0\right\}$ by setting $y^{*}=y^{* *}+\frac{w}{\theta}$.
} 
Lemma 1 (Optimal compensation without project selection:) Suppose $\underline{w} \leq \frac{c \underline{y}_{0}}{\kappa}$, in which case the minimum wage never binds. ${ }^{16}$ The optimal stock compensation in this case can be expressed as $w(y)=\max \{\underline{w}, c y / \kappa\}=c y / \kappa$. The expected wage payment is thus $c \mu_{o} / \kappa$.

If call options are used, in addition to a piece rate $\theta$, the principal also chooses an optimal exercise price $\left(y^{*}\right)$ to motivate desired managerial actions at the lowest cost. If $y^{*}>\underline{y}$, the manager's expected wage when compensated using options is

$$
E[w]=\underline{w}+\theta\left[0 * F_{o}\left(y^{*}\right)+\int_{y^{*}}^{\bar{y}}\left(y-y^{*}\right) f_{o}(y) d y\right] .
$$

Imposing $y^{*}>\underline{y}$ and increasing $y^{*}$ have two opposing effects on the cost to the principal of incentivizing effort, and the preferred vehicle depends on their relative strength. First, a higher $y^{*}$ increases the flat region in compensation over which only the minimum wage needs to be paid, which decreases expected wage payments. Second, a higher piece rate $\theta$ is required to motivate managerial effort when $y^{*}$ increases because of the reduced incentive region. ${ }^{17}$ This effect increases expected wages paid to the manager. When increasing $y^{*}$ increases shareholder costs associated with the piece rate more than it reduces costs by substituting the minimum wage for the piece rate, stock is the preferred compensation vehicle.

\subsection{Project selection with tail risk}

We now allow project selection and show that stock compensation that was optimal in the setting of Section 3.1 may induce the manager to take tail risk. Suppose that the stock

\footnotetext{
${ }^{16} \underline{w} \leq \theta \underline{y}$ might be realistic if the manager's personal share of the project payout is tiny, as would be the case for the CEO of a huge bank. However, if the "manager" is all employees of the bank, the condition is not realistic; labor costs at large universal banks are frequently between 25 and 50 percent of revenue net of interest expense.

${ }^{17}$ The manager's effort decision depends on the expected value of firm payoffs with and without effort. Recall that high effort shifts the payoff distribution to the right. An increase in $y^{*}$ incrementally cuts off less low mass from the high-effort distribution than from the low-effort distribution. Thus, the difference in expected value of the firm shrinks, and since $\theta$ times the difference must cover the cost of effort, $\theta$ must rise.
} 
compensation described in Lemma 1 is used and the condition specified in Lemma 1 is satisfied.

Case $1(1-p) \underline{w}+c \mu_{t} / \kappa>c \mu_{o} / \kappa$ :

For this to be satisfied together with the condition that the tail-risk project generates a lower expected value, $(1-p) d+\mu_{t}<\mu_{o}$, we must have $\underline{w}>\theta^{*} d=c d / \kappa$. Thus the manager receives the minimum wage $(\underline{w})$ when the disaster outcome $(d)$ occurs. ${ }^{18}$ The expected wage the manager receives if he takes tail risk is $E\left[w_{t}(y) \mid h, T\right]=(1-p) \underline{w}+\theta^{*} \mu_{t}$. The expected wage the manager receives if he takes ordinary risk is $E\left[w_{o}(y) \mid h, O\right]=\theta^{*} \mu_{o}$, where $\theta^{*}=c / \kappa$. In this case, $E\left[w_{t}(y) \mid h, T\right]>E\left[w_{o}(y) \mid h, O\right]$ and thus the manager will take tail risk if stock compensation is used.

Case $2(1-p) \underline{w}+c \mu_{t} / \kappa \leq c \mu_{o} / \kappa$ :

In this case, the expected wage payment conditional on taking ordinary risk is at least as large as that conditional on taking tail risk, so stock compensation is preferred by shareholders.

A stock compensation scheme without taking into account risk taking incentives can provide the manager incentives to take tail risk, which occurs in our setting when the disaster payoff is sufficiently small relative to the minimum wage. There is a clear interdependence between these two incentive conflicts. The moral-hazard problem takes on an extra dimension if the manager is able to conceal a low effort choice behind a relatively high return realization made possible by a suboptimal risk choice.

\section{Optimal compensation in the presence of tail risk}

In this section, we analyze the full model, including effort choice, project choice and the possibility of a binding minimum wage. In Section 4.1 we first analyze the effects of option

\footnotetext{
${ }^{18}$ This condition is always satisfied if $\underline{w}>0$ and $d=0$.
} 
compensation on risk taking and characterize conditions under which options can promote choice of the ordinary risk project. We discuss how risk characteristics of projects' payoffs influence the optimal exercise price. We show that, due to a trade-off between implementing managerial effort and avoiding tail risk, under certain conditions, it is infeasible to use stocks to avoid tail risk, whereas options work. This contrasts with prior research. Section 4.2 characterizes the equilibrium exercise price and shares granted, and Section 4.3 shows circumstances under which stocks cannot be used to deter tail risk. In Section 4.4, we show that collars enable incentivizing the ordinary risk project in a wide set of circumstances.

\subsection{Do call options imply tail risk?}

For expositional convenience, we first derive results for call options (the more general case of collars is analyzed below). By making compensation sensitive only to payoffs above a floor, call options can effectively alter the manager's expected payoff from the ordinary risk project relative to that from the tail risk project. In this section we derive necessary and sufficient conditions for call options to be an effective tool for incentivizing choice of the ordinary risk project.

For the constraint on the risk choice $\left(I C_{R 1}\right)$ to be satisfied using a call option contract design, the expected wage payment conditional on taking ordinary risk must be at least as large as the expected wage payment conditional on taking tail risk. That is,

$$
E\left[w\left(y_{o}\right) \mid y^{*}, h\right] \geq E\left[w\left(y_{t}\right) \mid y^{*}, h\right]
$$

When call options are used, we have $w(y)=\underline{w}+\theta \max \left\{y-y^{*}, 0\right\}=\left(\underline{w}-\theta y^{*}\right)+\theta \max \left\{y, y^{*}\right\}$. The requirement on expected wage payments becomes equivalent to

$$
E\left[y_{o} \mid y_{o} \geq y^{*}, h\right] \geq E\left[y_{t} \mid y_{t} \geq y^{*}, h\right]
$$

The following derivation provides an expression for $E\left[y_{i} \mid y_{i} \geq y^{*}, h\right]$, where $i \in\{o, t\}$. The 
notation specifying conditionality on high effort $(h)$ is suppressed for brevity.

$$
\begin{aligned}
E\left[y_{i} \mid y_{i} \geq y^{*}\right] & =y^{*} F_{i}\left(y^{*}\right)+\int_{y^{*}}^{\overline{y_{i}}} y f_{i}(y) d y \\
& =y^{*} F_{i}\left(y^{*}\right)+\left[y F_{i}(y)\right]_{y^{*}}^{\overline{y_{i}}}-\int_{y^{*}}^{\overline{y_{i}}} F_{i}(y) d y \\
& =\overline{y_{i}}-\int_{y^{*}}^{\overline{y_{i}}} F_{i}(y) d y .
\end{aligned}
$$

Collecting terms by letting $G_{i}(y)=1-F_{i}(y)$, we have

$$
\begin{aligned}
E\left[y_{i} \mid y_{i} \geq y^{*}\right] & =\overline{y_{i}}-\int_{y^{*}}^{\overline{y_{i}}}\left[1-G_{i}(y)\right] d y \\
& =\overline{y_{i}}-[y]_{y^{*}}^{\overline{y_{i}}}+\int_{y^{*}}^{\overline{y_{i}}} G_{i}(y) d y \\
& =y^{*}+\int_{y^{*}}^{\overline{y_{i}}} G_{i}(y) d y .
\end{aligned}
$$

Therefore, to satisfy the incentive constraint on the risk choice $\left(I C_{R 1}\right)$ using conventional call option compensation, the following condition must be met:

$$
\int_{y^{*}}^{\overline{y_{o}}} G_{o}(y) d y \geq \int_{y^{*}}^{\overline{y_{t}}} G_{t}(y) d y
$$

where $G_{o}(\cdot)=1-F_{o}(\cdot)$ and $G_{t}(\cdot)=1-F_{t}(\cdot)$, and $F_{o}(\cdot)$ and $F_{t}(\cdot)$ are the cumulative distribution functions of stock prices associated with the ordinary risk and tail risk projects respectively; and $y^{*}$ is the exercise price specified in the call options. ${ }^{19}$

When the manager makes an unobserved effort decision and an unobserved risk choice, the compensation off the equilibrium path also needs to be considered in order to ensure no dual deviation from the recommended actions. That is, the other constraint on the risk choice $\left(I C_{R 2}\right)$ must be satisfied to ensure the desired level of risk taking. $\left(I C_{R 2}\right)$ implies that as long as the following condition holds,

$$
\int_{y^{*}}^{\overline{y_{o}}} G_{o}(y) d y>\int_{y^{*}}^{\overline{y_{t}}-\kappa} G_{t}(y+\kappa) d y
$$

then the value of $\theta$ can be adjusted relative to the cost of exerting effort $(c)$ to satisfy the incentive constraint off the equilibrium path (for ease of exposition, we delay analysis of

\footnotetext{
${ }^{19} \mathrm{~A}$ condition analogous to this one is derived for unbounded distributions in Appendix E.
} 


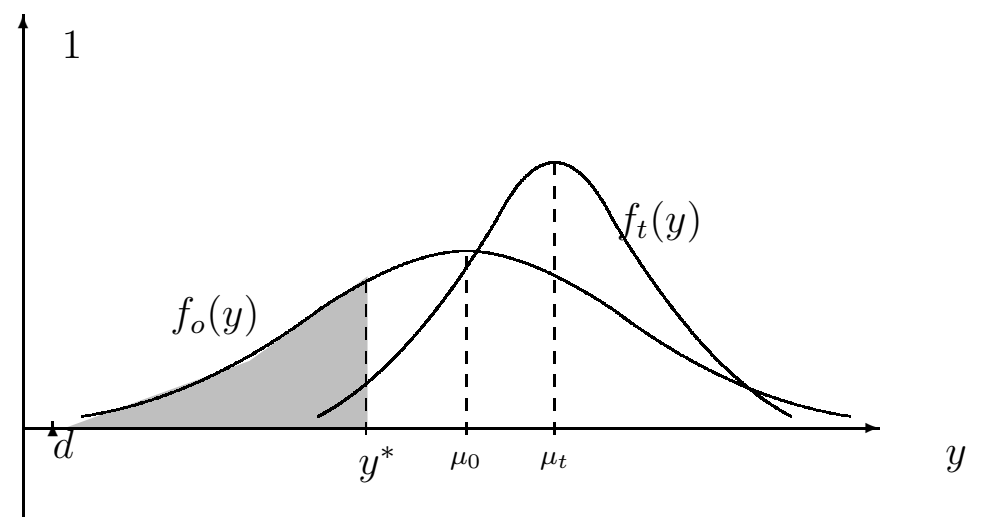

Figure 2: Stocks versus Options (PDF)

$\theta$ to the next subsection). If the incentive constraint on risk choices on the equilibrium $\left(I C_{R 1}\right)$ is met, the above inequality automatically holds:

$$
\int_{y^{*}}^{\overline{y_{o}}} G_{o}(y) d y \geq \int_{y^{*}}^{\overline{y_{t}}} G_{t}(y) d y=\int_{y^{*}-\kappa}^{\overline{y_{t}}-\kappa} G_{t}(y+\kappa) d y>\int_{y^{*}}^{\overline{y_{t}}-\kappa} G_{t}(y+\kappa) d y .
$$

Now Proposition 1 immediately follows.

Proposition 1 (Conditions for call options:) A necessary and sufficient condition under which call options can be used to deter choice of the tail risk project is

$$
\int_{y^{*}}^{\overline{y_{o}}} G_{o}(y) d y \geq \int_{y^{*}}^{\overline{y_{t}}} G_{t}(y) d y
$$

where $G_{o}(\cdot)=1-F_{o}(\cdot)$ and $G_{t}(\cdot)=1-F_{t}(\cdot)$, and $F_{o}(\cdot)$ and $F_{t}(\cdot)$ are the cumulative distribution functions of stock prices associated with the ordinary risk and tail risk projects respectively; and $y^{*}$ is the exercise price specified in the stock options.

That is, the tail risk project exhibits restricted second-order stochastic dominance over the ordinary risk project over the range above $y^{*}$.

Intuition is easiest to convey using symmetric payoff distributions as an example. For such distributions, Proposition 1 requires that the ordinary risk project has fatter tails than the tail risk project, as in Figure 2, where $\mu_{t}>\mu_{o}$ and $\mu_{d}^{t}<\mu_{o}$ hold. Since the 
manager's payoff is insensitive to realizations of $d$ because of the minimum wage constraint, the manager prefers the tail risk project. Use of options adds a floor $y^{*}$ below which the manager's payoff is also insensitive to project payoffs. Because a larger fraction of the mass of the payoff distribution for the ordinary risk project lies below $y^{*}$ than for the tail risk project, the effect is to increase the expected value of the ordinary risk project to the manager more than the expected value of the tail risk project.

However, if projects do not satisfy Proposition 1, then a call option cannot increase the value of the ordinary project relative to the tail risk project.

Proposition 1 implies that, contrary to the conventional wisdom that options incentivize risk taking, in our model options can provide incentives to avoid tail risk. In the standard moral hazard problem with risk neutrality, managers will be compensated exclusively with stock in order to elicit effort at least cost. The problem with stocks, however, is that when limited liability insulates managers from sharing the financial consequences of disasters, projects involving tail risk may appear attractive to the manager. By setting the floor to make compensation insensitive over a range of payoffs, the relative value of the projects to the manager can be adjusted to provide the desired incentives.

\subsection{Exercise price and shares granted}

In this section we analyze the exercise price specified in the optimal call option compensation, that is, the cutoff project outcome below which the manager receives only the minimum wage. Changing the floor alters the distribution and hence the expected value of project payoffs to which managerial compensation is sensitive. We first demonstrate in the following lemma (proved in Appendix C) that keeping the piece rate constant, the manager's expected payoff increases with the floor.

Lemma 2 (Monotonicity of expected values above exercise price:) $E\left[y_{i} \mid y_{i} \geq\right.$ $\left.y^{*}, e\right]>E\left[y_{i} \mid e\right]$, and $E\left[y_{i} \mid y_{i} \geq y^{*}, e\right]$ is increasing in $y^{*}, i \in\{o, t\}, e \in\{l, h\}$. 
The intuition is straightforward. The floor increases the expected project payoff relevant for compensation by making compensation unresponsive to relatively low project payoffs. For both projects, a higher floor thus induces a higher expected payoff level beyond which manager pay varies with the project payoff. If the differential in expected compensation conditional on taking ordinary and tail risk (i.e. $\Delta \equiv E\left[y_{o} \mid y_{o} \geq y^{*}, h\right]-E\left[y_{t} \mid y_{t} \geq\right.$ $\left.y^{*}, h\right]$ ) enlarges when the level of the floor increases (that is, $\frac{d \Delta}{d y^{*}}=F_{o}\left(y^{*}\right)-F_{t}\left(y^{*}\right) \geq 0$ ), a binding incentive constraint on risk choices $\left(I C_{R 1}\right)$ will determine the equilibrium floor. The lemma below (proved in Appendix C) describes the equilibrium floor in this case and the corresponding condition.

Lemma 3 (Equilibrium exercise price:) The equilibrium exercise price (the floor) will be such that $\left(I C_{R 1}\right)$ is satisfied with equality: $\int_{\underline{y}^{*}}^{\overline{y_{o}}} G_{o}(y) d y=\int_{\underline{y}^{*}}^{\overline{y_{t}}} G_{t}(y) d y$, if $F_{o}\left(\underline{y}^{*}\right) \geq$ $F_{t}\left(\underline{y}^{*}\right)$.

In the determination of the equilibrium floor, there are two forces at work, both coming from the principal's desire to reduce managerial rents. On one hand, holding managerial effort constant, a change in the floor modifies the manager's risk taking decision, which in turn affects the probability that the project payoff will exceed the floor. This effect leads the principal to offer a higher floor because increasing the floor decreases the probability that a choice of the tail risk project has a payoff above the floor relatively more than it decreases the probability that the payoff from the ordinary project is above the floor (if Proposition 1 holds). On the other hand, holding risk taking behavior constant, a higher floor reduces the incentive region in option compensation, benefiting the low-effort manager more than the high-effort manager. Therefore, a higher piece rate must be granted to motivate the manager to put forth effort as the floor increases. This trade-off results in an equilibrium floor that just satisifes the incentive compatibility constraint for risk taking.

We now analyze the equilibrium piece rate (share of each increment of project payoff above the floor that is received by the manager), denoted by $\theta^{*}$. The incentive constraint 
on effort $\left(I C_{e}\right)$ and the off-equilibrium incentive constraint on risk choices $\left(I C_{R 2}\right)$ jointly determine the equilibrium share, which is characterized in the following lemma.

Lemma 4 (Equilibrium shares granted:) The equilibrium piece rate ( $\left.\theta^{*}\right)$ can be expressed as

$$
\theta^{*}=\max \left\{\frac{c}{\int_{y^{*}}^{\overline{y_{o}}} G_{o}(y) d y-\int_{y^{*}}^{\overline{y_{o}}-\kappa} G_{o}(y+\kappa) d y}, \frac{c}{\int_{y^{*}}^{\overline{y_{o}}} G_{o}(y) d y-\int_{y^{*}}^{\overline{y_{t}}-\kappa} G_{t}(y+\kappa) d y}\right\} .
$$

If the condition specified in Lemma 3 is met, $\theta^{*}$ can be expressed as $\frac{c}{\kappa-\int_{y^{*}}^{y^{*}+\kappa} F_{o}(y) d y}$, which is strictly increasing in $y^{*}$.

Proof: See Appendix C.

Call options provide a nontrivial range of payoffs over which compensation does not vary with project payoff and thus does not vary with effort, which disproportionately benefits the low-effort manager. Stronger incentives are therefore necessary above the exercise price, and so the share of the project payoff received by the manager if the call option is in-the-money must be larger.

\subsection{Can stocks promote the desired choice?}

As noted previously, options are often thought to incentivize more risk-taking than stock. Here we use the tension between motivating effort and incentivizing risk choice to derive conditions under which stock fails to deter the manager from taking tail risk. For stock compensation, incentive compatibility on managerial effort $\left(I C_{e}\right)$ implies $\theta \geq \frac{c}{\int_{\underline{w} / \theta}^{\overline{y_{o}}}\left[G_{o}(y)-G_{o}(y+\kappa)\right] d y}$, which can be rewritten as

$$
\theta \int_{\underline{w} / \theta}^{\overline{y_{o}}}\left[G_{o}(y)-G_{o}(y+\kappa)\right] d y \geq c
$$

Because the left-hand side of this inequality is increasing in $\theta$ and the right-hand side is constant, inequality (3) determines a lower bound of $\theta$ that satisfies incentive compatibility for the effort decision. 
When the manager also makes a risk choice, the ordinary risk project is chosen only if the manager's payoff from the tail risk project is smaller. Following Proposition 1, $\theta$ in the optimal stock compensation must also satisfy $\left(I C_{R}\right)$ :

$$
\int_{\underline{w} / \theta}^{\overline{y_{o}}} G_{o}(y) d y \geq \int_{\underline{w} / \theta}^{\overline{y_{t}}} G_{t}(y) d y .
$$

Lemma 3 shows the condition under which the expected compensation differential between the two projects $(\Delta)$ is weakly increasing in $(\underline{w} / \theta)$. In this case, inequality (4) determines an upper bound of $\theta$ that provides the risk-taking incentives desired by the principal.

Indeed, the optimal piece rate $\theta$ is determined by a tradeoff between the negative effect of the piece rate on risk choice and its positive effect on effort, and thus depends on the magnitude of the two agency problems. Compared to the case of option compensation where incentive compatibility of effort choice $\left(I C_{e}\right)$ and risk decision $\left(I C_{R 1}\right)$ can be both binding in equilibrium, there is likely to be slack in incentive compatibility constraints when stocks are used, because the piece rate $\theta$ is the only measure the principal chooses. There is a natural interdependence between effort choices and risk choices. Compensation controls for both mutually dependent managerial actions when the manager is able to conceal a low effort choice behind a relatively high return realization made possible by a high risk choice. Separate analysis of moral hazard and risk selection in isolation does not capture this additional, important dimension.

Depending on $\kappa$ and the distributional characteristics the two projects, it may be the case that there does not exist a $\theta$ that simultaneously satisfies both incentive compatibility conditions. The condition under which stock compensation is ineffective in motivating choice of both the ordinary risk project and effort is:

Proposition 2 (Suboptimality of stock compensation:) It is infeasible to use stocks to avoid tail risk if $\theta_{\max }<\theta_{\min }$, where $\theta_{\max }$ and $\theta_{\min }$ are such that

$$
\int_{\underline{w} / \theta_{\max }}^{\overline{y_{o}}} G_{o}(y) d y=\int_{\underline{w} / \theta_{\max }}^{\overline{y_{t}}} G_{t}(y) d y,
$$




$$
\theta_{\min } \int_{\underline{w} / \theta_{\min }}^{\overline{y_{o}}}\left[G_{o}(y)-G_{o}(y+\kappa)\right] d y=c,
$$

In the contrasting case of call option compensation, the principal can choose the floor and the piece rate independently to achieve efficient effort and prudent risk taking. When stock is used, however, the inherent kink $(\underline{w} / \theta)$ below which the manager receives the minimum wage is also determined by the rate of pay for performance $(\theta)$. Therefore any change of $\theta$ influences both project selection and the effort decision. Changing the payperformance sensitivity is analogous to varying the strike of a call option because it varies $(\underline{w} / \theta)$, and the relative expected value to the manager of the two projects depends on the range of payoffs over which the manager's payoff is insensitive to the project payoff. However, the manager will exert high effort only if the compensation is sufficiently sensitive to performance to compensate for the cost of effort. The conflict makes it impossible to motivate effort while avoiding tail risk taking in this case. Proposition 2 gives a condition for stock compensation to incent tail risk taking. Note that it is more likely to be satisfied if managerial effort is more costly or less effective in improving project payoffs (i.e. a large $c$ relative to $\kappa$ ) and, excluding the disaster outcome, the ordinary risk project is less risky than the tail risk project in the sense of Proposition 1.

\subsection{Collar Options}

Some strategies employed by financial institutions are characterized by relatively fat-tailed payoff distributions in normal times as well as the possibility of a disaster outcome. For example, many investments that were financed with high leverage likely had volatile payoffs even in the years leading up to the crisis and also delivered disastrous returns during the crisis. Intuitively, even though compensation in call options often disincentivizes such strategies, compensation that resembles a collar option can do so by establishing a strike value (cap) above which the manager's payoff is insensitive to increases in project payoffs. As this strike is lowered, it reduces the manager's expected value more for the project with fat-tailed payoffs than for the project with thinner-tailed payoffs. Thus, a collar-like 
compensation contract that permits call options and put options can incentivize choice of the ordinary risk project in a larger array of circumstances than call options alone can achieve. Because the principal can set the floor to any value in the interval $(\underline{y}, \bar{y})$, and similarly for the cap, the collar can be engineered to mimic stock, a call alone, or stock plus a put. (Such an arrangement need not be exactly a collar because it can be implemented contractually with a single arrangement that involves a cap and a floor.)

If collars are used, compensation takes the form:

$$
w(y)=\underline{w}+\theta \min \left\{\max \left\{y-y^{f}, 0\right\}, y^{c}-y^{f}\right\},
$$

where $y^{f}$ is a floor below which the manager's payoff is insensitive to the project payoff, and $y^{c}$ is a cap above which the manager's payoff is insensitive to the project payoff. In this section, we establish the condition under which collar options can be used to deter tail risk, characterized in the following proposition.

Proposition 3 (Conditions for collars:)A necessary and sufficient condition for collar options to incentivize the choice of ordinary risk is

$$
\int_{y^{f}}^{y^{c}} F_{o}(y) d y \leq \int_{y^{f}}^{y^{c}} F_{t}(y) d y
$$

where $F_{i}(\cdot), i \in\{o, t\}$ represent the cumulative density functions for payoffs generated from the ordinary-risk project and tail-risk project respectively.

Proof: See Appendix C.

This condition only requires the restricted second-order stochastic dominance of tailrisk project over ordinary-risk project to hold for any positive part of the entire payoff support. By giving the principal additional compensation contract parameters to use, collars provide more flexibility, making it possible for condition (4.4) to be satisfied for a larger variety of project characteristics. Thus, collars can deter undesired risk-taking for a larger set of project characteristics than call options. When the tail-risk project dominates 
the ordinary-risk project stochastically at the first order over the continuous region, and the manager is prevented from being financially exposed to the disaster state because of the minimum wage constraint, collars can provide appropriate risk-taking incentives if the condition specified below is satisfied.

Proposition 4 (Generality of collars) A sufficient condition for collars to incent the choice of ordinary risk is $\underline{y_{t}}<\underline{y_{0}}$ or $\overline{y_{t}}<\overline{y_{o}}$.

Proof: See Appendix C.

Because of nonlinearities induced by the presence of both a floor and a cap in a collar, we are unable to obtain closed-form solutions for floor and cap values and $\theta$.

\section{Simulation}

We simulate the model to evaluate comparative statics and, to shed light on the information requirements of a board of directors choosing options, we simulate how much contract characteristics vary with project characteristics. We have simulated projects with both uniformly and normally distributed payoffs. Results were qualitatively similar so we report only results for the uniformly distributed payoffs. In most simulations, we vary the properties of the tail-risk project while holding other parameters and the distribution of the ordinary risk project fixed (the primary driver is the relationship between the payoff distributions for the two projects, so much can be learned by varying only one of the two projects). Values of other parameters are shown in Table 1.

\subsection{Fragility}

The values in cells of the table in Figure 3 are floors from the contract chosen by the shareholder, while the values in Figure 4 are caps. The left column of each table shows the lower bound of the uniform distribution of tail-risk project payoffs, and the top row 


\begin{tabular}{cc} 
Parameter & Value \\
\hline$\underline{y_{o}}$ & 20 \\
$\overline{y_{o}}$ & 80 \\
$\frac{y_{t}}{\overline{y_{t}}}$ & 21 \\
$p$ & 0.9 \\
$d$ & 0.5 \\
$c$ & 1 \\
$\kappa$ & 3 \\
\hline
\end{tabular}

Table 1: Parameter values used in simulations

shows the upper bound, so each cell has the floor (cap) from a version of the model with the specified project distribution lower and upper bounds.

Although floors and caps tend to vary monotonically within a given row and column, monotonicity is sometimes violated. For example, notice that for a tail risk project distribution upper bound of 84 , the cap value decreases as the lower bound decreases until it reaches 24, then increases, then decreases again. Moreover, some of the changes in cap or floor values for relatively small changes in bounds are small, while others are large.

The red region of each table identifies contracts which are call options, while the green identifies puts and the blue collars (cases in which both floor and cap are inside the bounds for the ordinary project's payoff distribution). The white region signifies cases in which stock is preferred (cases where the floor is at or below the ordinary project lower bound, and the cap is at or above the tail risk project upper bound). Notice that the white region is rather small: At least for this simulation, stock is rarely the compensation delivery vehicle that efficiently delivers both effort and the desired risk choice. Moreover, while the different styles of contract tend to be clustered (the region for each color is contiguous), there are many variations in tail risk project bounds that lead to changes in contract style, and this in a case where all other parameters of the model are held fixed.

Overall, as noted previously, the sensitivity of contract details to variations in parame- 


\begin{tabular}{|l|l|l|l|l|l|l|l|l|l|l|}
\hline$y_{f}$ & 72 & 74 & 76 & 78 & 80 & 82 & 84 & 86 & 88 & 90 \\
\hline 12 & 58.500 & 58.500 & 58.500 & 58.500 & 58.500 & 58.500 & 53.372 & 45.809 & 42.396 & 36.180 \\
\hline 14 & 58.500 & 58.500 & 58.500 & 58.500 & 58.500 & 58.500 & 50.802 & 44.706 & 38.008 & 33.331 \\
\hline 16 & 58.500 & 58.500 & 58.500 & 58.500 & 58.500 & 58.332 & 47.898 & 38.552 & 33.500 & 31.530 \\
\hline 18 & 58.500 & 58.500 & 58.500 & 58.500 & 58.500 & 57.071 & 43.014 & 34.985 & 31.878 & 29.050 \\
\hline 20 & 58.500 & 58.500 & 58.500 & 58.500 & 58.500 & 54.351 & 38.613 & 32.300 & 25.261 & 25.110 \\
\hline 22 & 58.500 & 58.500 & 58.500 & 58.500 & 58.500 & 46.816 & 28.851 & 28.626 & 24.593 & 22.694 \\
\hline 24 & 58.500 & 58.500 & 58.500 & 58.500 & 58.500 & 33.727 & 16.376 & 19.672 & 19.680 & 19.654 \\
\hline 26 & 58.500 & 58.500 & 58.500 & 58.500 & 58.500 & 11.000 & 2.563 & 17.313 & 17.422 & 16.872 \\
\hline 28 & 58.500 & 58.500 & 58.500 & 58.500 & 11.000 & 2.000 & 0.500 & 12.411 & 13.641 & 13.207 \\
\hline 30 & 58.500 & 58.500 & 58.500 & 58.500 & 2.000 & 0.500 & 3.445 & 7.811 & 10.240 & 9.898 \\
\hline
\end{tabular}

Figure 3: Value of floor in the preferred contract for different project characteristics

\begin{tabular}{|l|l|l|l|l|l|l|l|l|l|l|}
\hline$y_{c}$ & 72 & 74 & 76 & 78 & 80 & 82 & 84 & 86 & 88 & 90 \\
\hline 12 & 80.000 & 80.000 & 80.000 & 80.000 & 80.000 & 82.000 & 76.629 & 75.791 & 72.331 & 72.820 \\
\hline 14 & 80.000 & 80.000 & 80.000 & 80.000 & 80.000 & 82.000 & 76.198 & 73.294 & 72.792 & 71.579 \\
\hline 16 & 80.000 & 80.000 & 80.000 & 80.000 & 80.000 & 82.000 & 75.245 & 74.948 & 72.500 & 68.470 \\
\hline 18 & 80.000 & 80.000 & 80.000 & 80.000 & 80.000 & 82.000 & 74.986 & 72.729 & 68.122 & 64.951 \\
\hline 20 & 80.000 & 80.000 & 80.000 & 80.000 & 80.000 & 78.650 & 72.187 & 67.700 & 67.025 & 61.390 \\
\hline 22 & 80.000 & 80.000 & 80.000 & 80.000 & 80.000 & 78.340 & 71.149 & 60.574 & 57.407 & 54.163 \\
\hline 24 & 80.000 & 80.000 & 80.000 & 80.000 & 80.000 & 72.273 & 69.103 & 53.952 & 48.330 & 44.674 \\
\hline 26 & 80.000 & 80.000 & 80.000 & 80.000 & 80.000 & 82.000 & 78.324 & 40.807 & 38.530 & 38.500 \\
\hline 28 & 80.000 & 80.000 & 80.000 & 80.000 & 80.000 & 82.000 & 66.857 & 41.691 & 38.512 & 38.500 \\
\hline 30 & 80.000 & 80.000 & 80.000 & 80.000 & 80.000 & 59.250 & 49.832 & 42.152 & 38.500 & 38.500 \\
\hline
\end{tabular}

Figure 4: Value of cap in the preferred contract for different project characteristics 
ters makes us skeptical that real-world boards of directors operating with less information than managers would be able to reliably choose a contract that delivers both effort and the desired level of risk-taking in a world with tail risk and limited liability.

\subsection{Behavior of constraints}

Additional insight can be gained by inspecting the behavior of the model's three constraints for different parameter values. The following charts are from simulations that grid-search collar option floors and caps for combinations that satisfy the constraints.

We first analyze a case in which the CDF of the tail-risk project and CDF of the ordinary-risk project have no intersection. The incentive constraint on risk taking is always satisfied in this case, and therefore the feasible region for $I C_{R}$ to be satisfied is the entire triangular area above the 45 degree line (i.e. the cap is higher than the floor, which must always hold) as shown in Figure 5. The more blue the color the more binding is the constraint (shareholders will choose the most-blue intersection of constraints).

Figure 6 shows the feasible region in which $I C_{e 1}$ is satisfied. Because the ordinary-risk payoff under low effort is less than the payoff under high effort, it will not be possible to incentivize effort for caps (and thus floors) that are too near the lower bound of the payoff distribution, so only a portion of contracts above the 45 degree line with higher caps will be incentive-compatible.

Figure 7 shows the incentive-compatible region for $I C_{e 2}$, which is the incentive-compatible region for $I C_{R}$ subtracted in a neighborhood of the 45 degree line (where the difference between upper strike and lower strike is minimal) to compensate for the cost of effort.

The compensation contract that provides appropriate risk taking incentives and effort incentives is the intersection of the three incentive-compatible regions shown in Figures 5, 6, and 7, which is illustrated in Figure 8. The expected payment to the manager decreases as the color becomes a darker blue, so the shareholders prefer the most blue combination of floor and cap. In this example, the shape of the region is rather compact. 


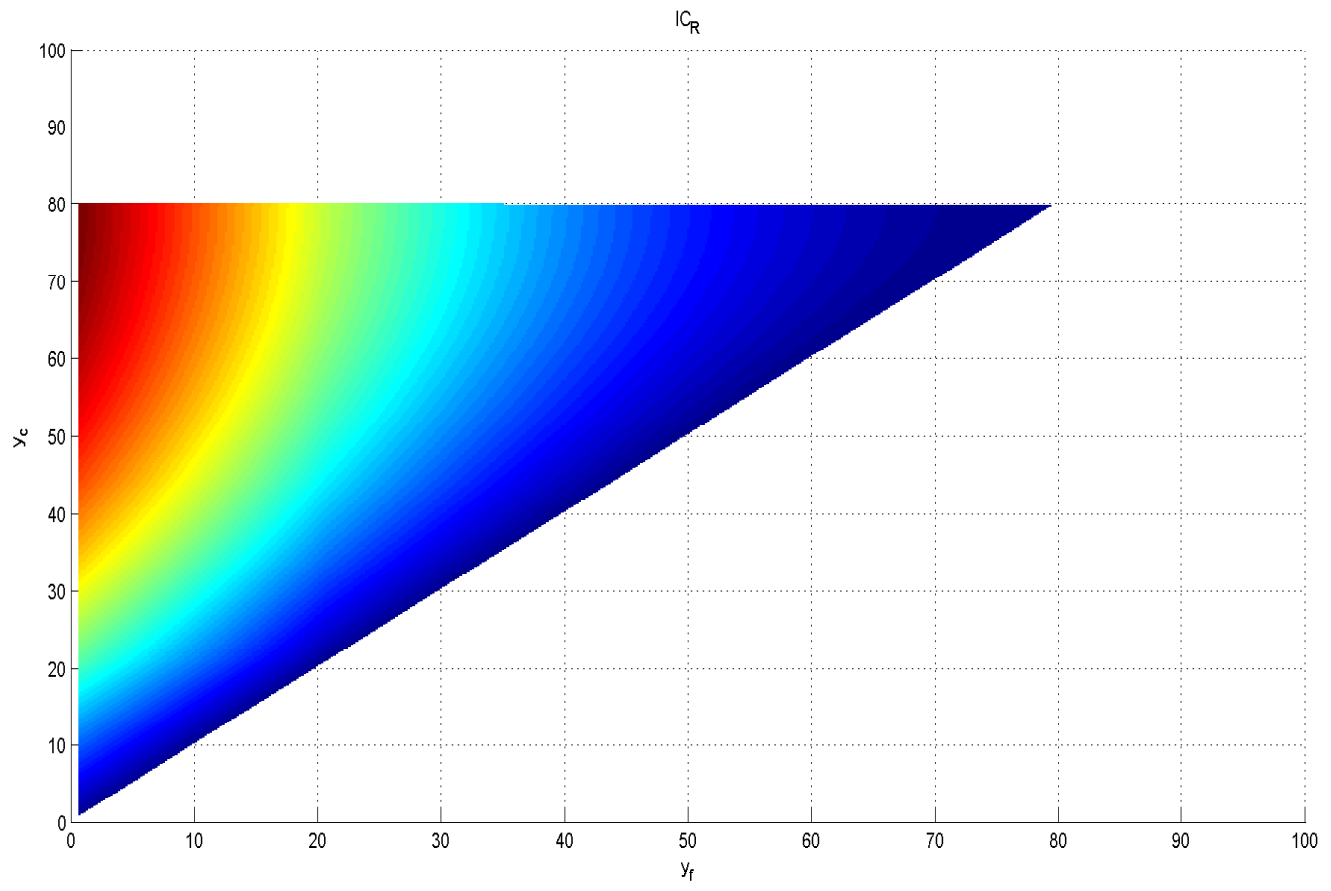

Figure 5: The incentive-compatible region for $I C_{R}$

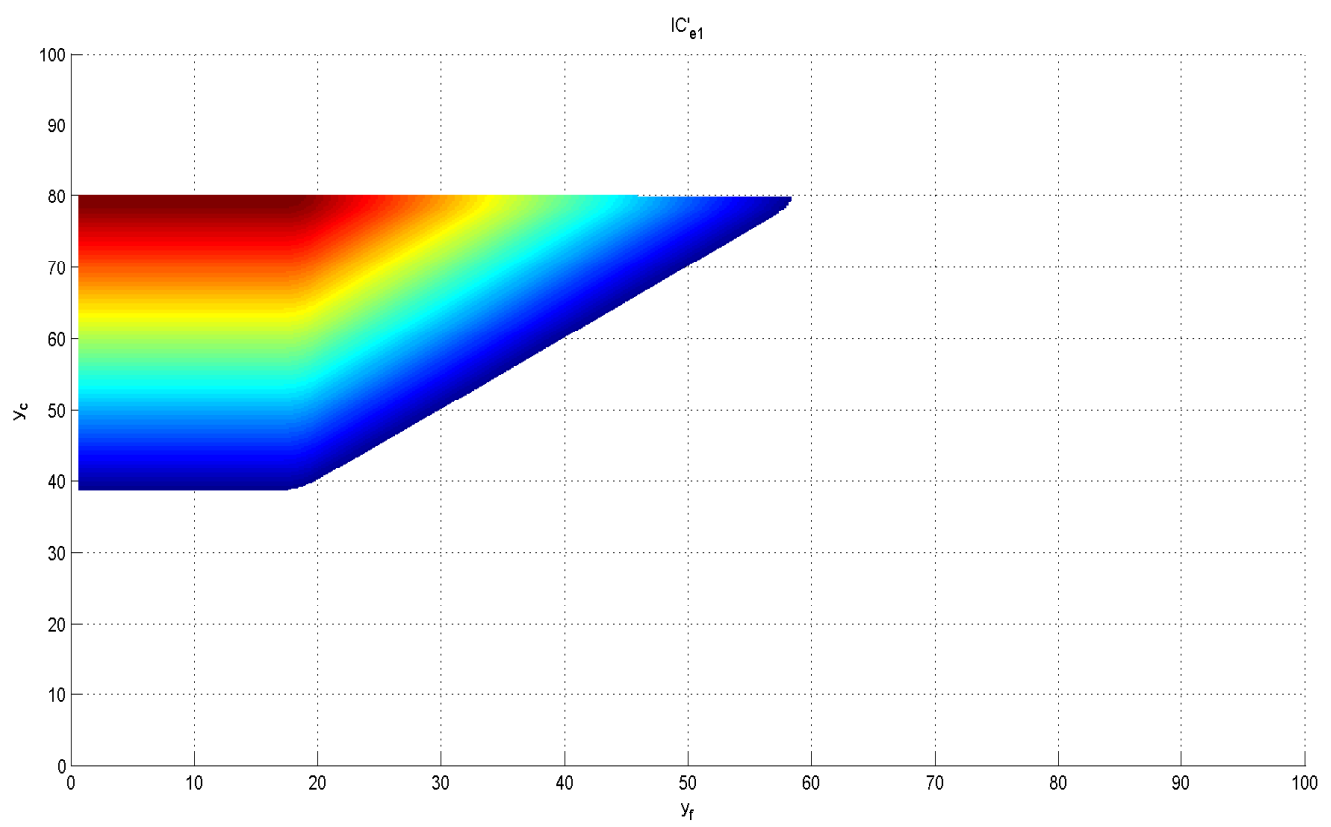

Figure 6: The incentive-compatible region for $I C_{e 1}$ 


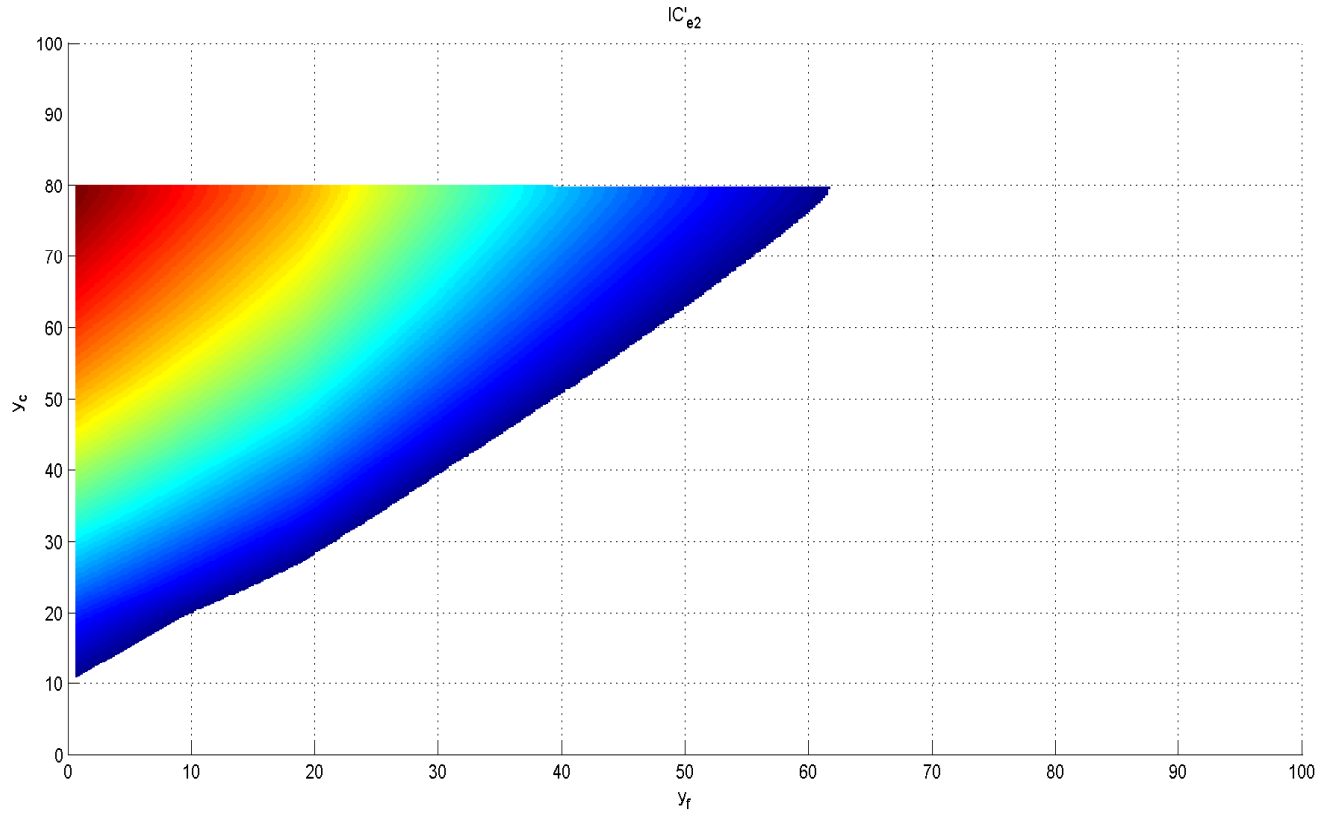

Figure 7: The incentive-compatible region for $I C_{e 2}$

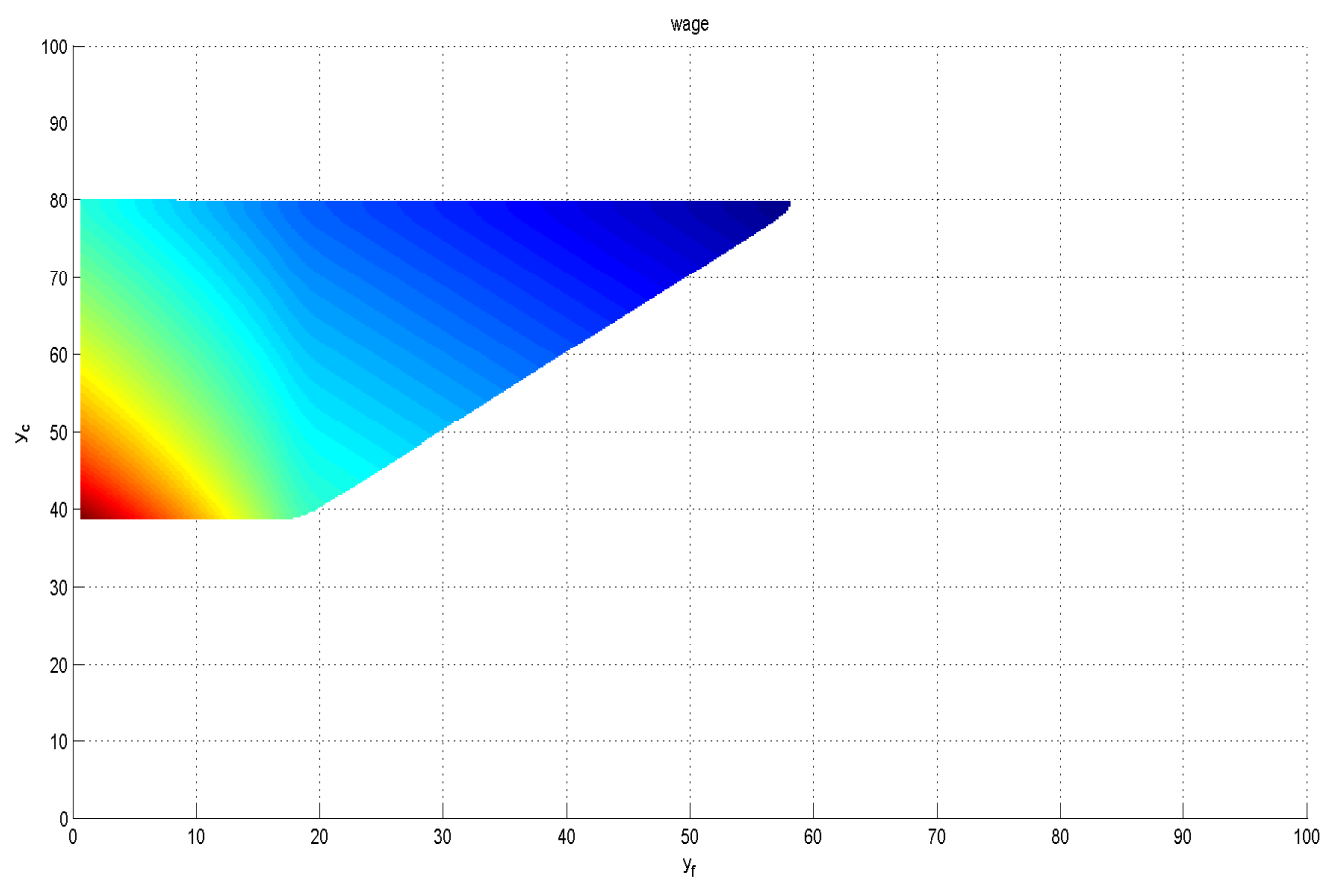

Figure 8: The incentive-compatible region for all incentive constraints 


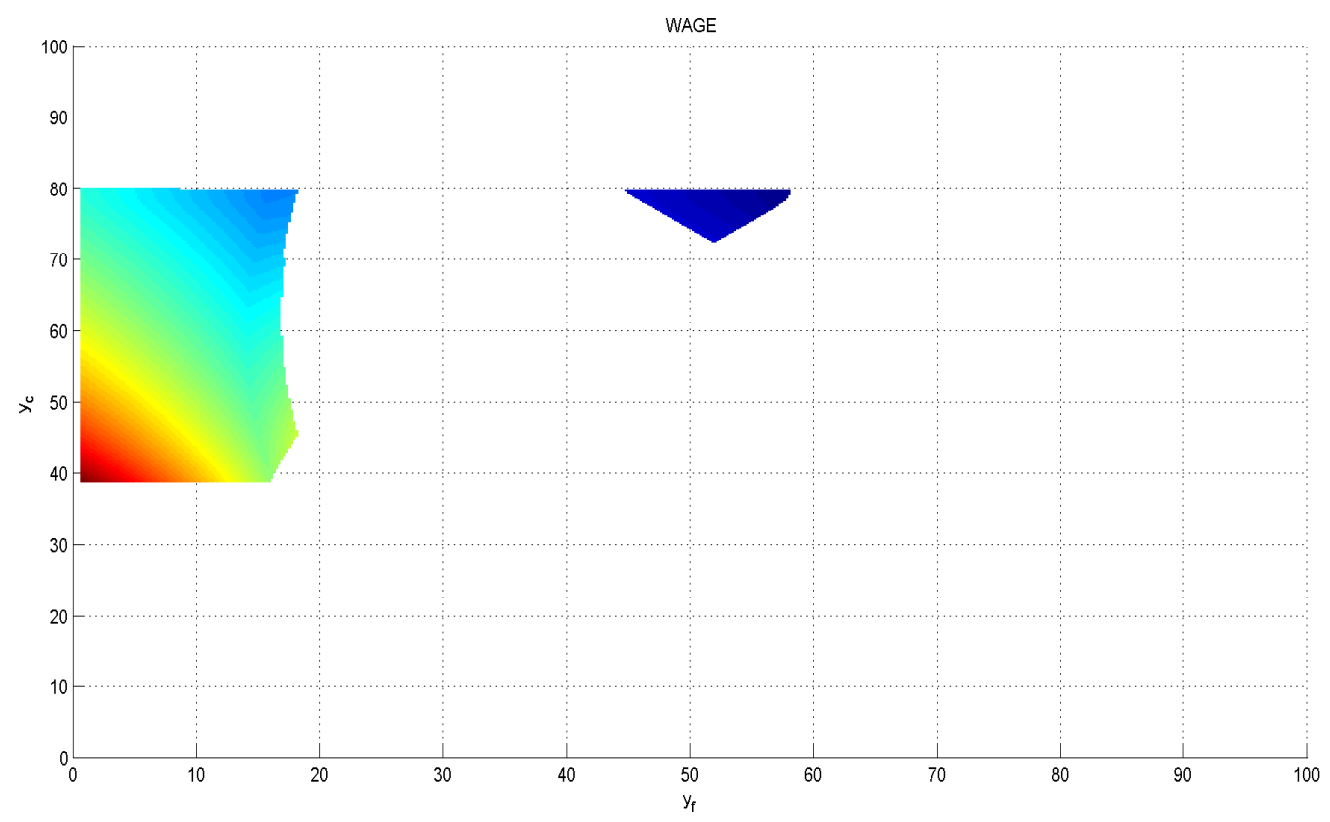

Figure 9: The incentive-compatible region for all incentive constraints with a small change in $\underline{y_{t}}$

However, when we change the lower bound of the continuous portion of tail-risk payoff to 28 (from 21), keeping all else fixed, the incentive-compatible region that satisfies all the three incentive constraint becomes a set of disjoint areas as shown in Figure 9. This is analogous to what is shown in Figures 3 and 4: Rather modest changes in parameters can lead to substantial changes in the constraints and thus in the nature of the preferred contract.

\subsection{Comparative Statics}

Details of other comparative statics appear in the Appendix. To summarize: Similar to the floors and caps, as the distribution of tail-risk project payoffs changes, the value of $\theta$ can vary widely. As the tail-risk project becomes more profitable and has an expected value closer to the ordinary-risk project keeping the disaster payoff and probability fixed, the expected payout to the manager increases (it becomes increasingly expensive to deter 
tail risk). As the cost of effort $c$ falls (and the value of effort $\kappa$ rises), it becomes less expensive to induce effort, so the equilibrium piece rate $(\theta)$ decreases, the incentive region shrinks, and the expected payment to the manager falls. As $p$ increases, the probability of disaster decreases, and the expected value of the tail-risk project increases. It becomes more expensive to disincentivize it, and thus the expected wage increases.

\section{Extensions}

\subsection{Ex post penalties that reduce outside wealth of the manager}

In our model, the properties of project payoff distributions are known to shareholders. In reality, however, most boards of directors have a limited understanding of the risk properties of projects. The simulations reported above imply that even modest misunderstandings of risks could cause a board to unintentionally select a pay function that provides incentives to take bad tail risk. Here we explore the possibility that introducing an additional contract feature might support more robust provision of desired incentives.

Limited liability of the manager is a key feature of our setting. In the absence of limited liability, shareholders could impose a penalty on the manager upon realization of bad tail risk large enough to make the manager's expected value from the tail risk project very low ("debtors prison"). The remainder of the contract would then focus on incentivizing effort and, in our setup, stock would be effective. We do not wish to eliminate limited liability (debtors prison is illegal, after all), but something similar can be achieved by allowing shareholders to require the manager to post outside wealth at the beginning of the game and by allowing some of that wealth to be forfeited if bad tail risk is realized. The amount of wealth exposed to forfeiture then becomes a policy parameter that can be used to incent the desired risk choice. Results presented earlier in the paper still hold - if a collar option was effective when the penalty is zero it is still effective if the penalty is positive - but it is possible that shareholders would need less information to achieve the desired risk and effort choice if the contract combines stock with forfeiture of outside wealth. Of course, 
the feasibility of forfeiture depends upon manager wealth and willingness to participate.

Casual observation reveals a number of features of real-world pay arrangements that expose managerial wealth to forfeiture. For example, some banks have implemented clawback policies that enable them to recapture previously paid-out salaries and bonuses in some circumstances. Many banks have increased the fraction of bonuses for which payout is deferred and created malus provisions that reduce or eliminate the deferred pay if risk outcomes are bad. The details of such policies seem likely to matter and involve modeling complications that we leave to future research (for example, shareholder incentives to expropriate). In this subsection, we assume managerial pre-existing wealth is infinite and that the cost of exposing it to forfeiture is zero, so that the amount forfeited in event of a bad tail realization is a free parameter of the contract. We derive the minimum amount that must be exposed to make stock effective and examine the size of that minimum relative to the project payoff.

First, we derive conditions on the amount of clawback such that the incentive constraint on risk choices is non-binding. We revisit our example in Section 3 in which stock compensation, with a wage function $w(y)=c y / k$, is an optimal compensation without tail risk but will induce tail-risk taking when tail risk is available. With the option of punishment in the disaster state, stock compensation is preferred if the incentive constraint on risk choices is always satisfied, which occurs when the amount of clawback in the disaster state, denoted by $L$, is sufficiently large:

$$
L \geq \underline{w}-\frac{c}{\kappa(1-p)}\left(\mu_{o}-\mu_{t}\right)
$$

We next analyze the case of stock compensation when the minimum wage constraint is binding over some part of the payoff domain. We solve for the minimum amount of clawback in the disaster state required to have a non-binding incentive constraint on risk:

$$
L \geq \underline{w}+\frac{\underline{w}}{\kappa(1-p)}\left[p F_{t}\left(\frac{\underline{w}}{\theta}\right)-F_{o}\left(\frac{w}{\theta}\right)\right]-\frac{\theta}{(1-p)}\left[\int_{\frac{w}{\theta}}^{\overline{y_{o}}} y f_{o}(y) d y-\int_{\frac{w}{\theta}}^{\overline{y t}} y f_{t}(y) d y\right]
$$


where $\theta$ is determined by a binding incentive constraint on effort, i.e. $\theta \int_{\frac{w}{\theta}}^{\overline{y_{o}}}\left[G_{o}(y)-G_{o}(y+\right.$ $\kappa)] d y=c$.

If $L$ is a free parameter subject to the principal's discretion and thus the incentive constraint on risk taking is always satisfied, either stocks or options can be used to incentivize effort. The most cost-effective vehicle depends on the payoff distribution. To see this clearly, we note the expected labor cost of inducing effort using options is:

$$
E[w]=\underline{w}+\theta \int_{\underline{y}}^{\overline{y_{o}}} y f_{o}(y) d y .
$$

Since the equilibrium piece rate is determined by a binding incentive constraint on effort, we can rewrite the expected wage payment as follows.

$$
E[w]=\underline{w}+\frac{c \int_{\underline{y}}^{\overline{y_{o}}} y f_{o}(y) d y}{\int_{\underline{y}}^{\overline{y_{o}}}\left[G_{o}(y)-G_{o}(y+\kappa)\right] d y},
$$

which is not necessarily monotonic in $\underline{y}$, depending on the project payoff distribution. Therefore, it is possible that both stocks (a corner solution to the minimization problem) and options can emerge as the optimal compensation vehicle for different payoff distributions. The reason is that there is a trade-off in setting the strike price. A lower strike price enlarges the incentive region over which incentive pay needs to be paid, but it reduces the piece rate required to compensate for the effort cost. Which effect dominates in minimizing the expected labor cost depends on the payoff distribution and the value of $\kappa$.

\subsection{Monitoring of risk choices}

Monitoring by the principal is an alternative to incentive alignment by compensation contract design. In this section we analyze the effect of monitoring on the choice between stock and call options. To do so, we expand the model to include monitoring decisions and actions that take place at different times.

Figure 10 describes the sequence of the events. The principal announces the monitoring decision and managerial compensation structure at the beginning of time: $m=1$ if the 
Figure 10: Model Timeline

\begin{tabular}{llll}
\hline Principal announces & Manager makes & Principal monitors & Outcome realizes Compensation \\
compensation \& & risk choice \& & if announced so & is made to \\
monitoring decision & effort decision & manager
\end{tabular}

principal announces that the manager's risk choice will be monitored and $m=0$ otherwise. To avoid the time-inconsistency problem, we assume that the principal is committed to her announced monitoring decision. ${ }^{20}$ Monitoring involves a cost to the principal, that is, $C(m=1)=c_{m}$, while no monitoring does not, $C(m=0)=0$. If the manager chooses the tail risk project, it will be successfully detected by monitoring with probability $p_{s} \in[0,1]$, and the manager will be punished with the minimum wage $\underline{w}$ in this case. With probability $\left(1-p_{s}\right)$, the tail risk project choice is not detected and pay is according to the compensation contract offered at the beginning of the period.

A stock compensation contract can promote the choice of the ordinary risk project if monitoring is sufficiently effective. Proposition 5 (proved in Appendix C) states the necessary efficiency of monitoring for stock compensation to deter tail risk.

Proposition 5 (Monitoring restores optimality of stock compensation:) If $p_{s} \geq$ $1-\left(\frac{\frac{c}{\kappa} \mu_{o}-\underline{w}}{\frac{c}{\kappa} \mu_{t}-p \underline{w}}\right)$, the stock compensation described in Lemma 1 can be used to deter tail risk.

A probabilistic detection essentially causes the pay-performance sensitivity for the tail risk project to be lower than the ordinary risk one, making the ordinary risk project more attractive from the manager's perspective. When $p_{s}<1-\left(\frac{\frac{c}{\kappa} \mu_{o}-\underline{w}}{\frac{c}{\kappa} \mu_{t}-p \underline{w}}\right)$, option compensation is necessary to align risk-taking incentives, provided that the following condition

\footnotetext{
${ }^{20}$ Without commitment, the principal always has an incentive to announce monitoring before the manager's risk choice but not to monitor afterwards.
} 
holds.

Proposition 6 (Conditions for call option with monitoring) A necessary and sufficient condition for call options to be optimal in the presence of monitoring is

$$
\int_{y^{*}}^{\overline{y_{o}}} G_{o}(y) d y \geq\left(1-p_{s}\right) \int_{y^{*}}^{\overline{y_{t}}} G_{t}(y) d y .
$$

Proof: See Appendix C.

Compared to the condition in the absence of monitoring (condition 2), the condition becomes less restrictive when monitoring is possible and thus requires a lower floor. When monitoring becomes more effective in detecting tail risk, expected compensation conditional on taking on ordinary risk remains constant while that conditional on taking on tail risk decreases, for a given value of the floor. A lower floor tends to be required to avoid tail risk, and expected managerial compensation is consequently lower than in the absence of monitoring. With a positive cost of monitoring, it is optimal for shareholders to monitor if the reduction of expected managerial compensation exceeds the cost incurred during monitoring.

\subsection{Discussion: externality and limited liability of shareholders}

Many observers believe that large losses at major banks impose negative externalities on society. In our main setup, such externalities do not arise because project payoffs are assumed to accrue entirely to shareholders. Moreover, all payoffs are positive, so whether shareholders have limited or unlimited liability is immaterial. Exploring the sources of such externalities, or modeling them in any detail, is well beyond the scope of this paper. However, we can make a few comments about the implications of their existence. ${ }^{21}$

Suppose no negative externalities are produced by outcomes in the normal range, but the disaster outcome does produce such externalities. They might be represented by defining the social payoff in event of disaster to be $s=d-e$, where $d$ is the portion of the total

\footnotetext{
${ }^{21}$ Gete and Gomez (2013) analyze compensation structures in a setting with fire sale externalities.
} 
disaster payoff that accrues to shareholders and $-e$ is the loss of welfare that is absorbed by parties external to the firm (and external to our model). Naturally the shareholders will not take $-e$ into account when choosing the manager's contract. Even if they did, there would be no impact on the compensation choice in cases where the shareholders would prefer the ordinary project. ${ }^{22}$ However, allowing externalities does open a wedge between the preferences of shareholders and the social planner for the two projects. The wedge is material only for those project combinations where the planner prefers the ordinary risk project and shareholders prefer the tail risk project. For such combinations, shareholders would choose stock (because effort can be motivated more cheaply and the manager will choose the tail risk project as shareholders desire), whereas the planner would choose options in order to motivate choice of the ordinary risk project.

We speculate that the likelihood that the planner can reduce the incidence of externalities depends on the planner's power and information. If the planner has full information and the power to compel contract terms, then the planner can simply dictate that properly designed options be used. However, if the planner can only dictate the contract form, shareholders will simply set option terms to mimic stocks, so the planner can have no effect on the allocation. A planner that has power but does not know the project distributions cannot be sure of improving welfare by dictating that options be used, since the planner will not know how to set the terms of the option contract.

Overall, it seems unlikely that external costs of bank distress can be reduced by regulating the form of compensation contracts (stocks versus options). It is possible that a planner who compelled a reduction in the minimum wage might do some good, since the manager would then be exposed to more of the disaster outcome's downside, but for such an approach to be effective the shareholders would have to be compelled to include the cost of the externality in the measured payoff that determines the manager's pay, which

\footnotetext{
${ }^{22}$ throughout the paper, we assume that parameters and distributions are such that shareholders prefer the ordinary risk project, because in the absence of externalities, motivating the manager to choose the ordinary project is uninteresting if the shareholders do not prefer it.
} 
might impose large information requirements on regulators. Moreover, such an approach would work in practice only if the manager's alternative wage were below the minimum wage chosen by the planner. Though beyond the scope of this paper, future research that takes a more detailed look at externalities and strategies to address them seems likely to be fruitful.

\section{Conclusion}

This paper analyzes the circumstances in which compensation in the form of stock and of options is effective in giving managers incentives to exert effort and to choose projects with risk characteristics that are desired by shareholders when risk choice and effort choice are not observable. In contrast to conventional wisdom in the literature that options incent more risk taking than stock, we show that stock compensation has a dark side, in that it can generate managerial incentives to take tail risks, since managers are protected by limited liability from bearing the adverse consequences when disaster states occur. We do not suggest that compensation in stock will always incentivize risk-taking that is not desired by shareholders, but rather that stock will do so in some circumstances and that in some circumstances options could incentivize the desired project choice.

We characterize optimal pay functions in a one-period setting. Our work is relevant to the current debate about regulation of compensation, as well as to boards of directors considering different forms of compensation, as we incorporate features like limited liability, base salaries, and risk and effort choice contingent on payoffs. However, we do not examine interim arrivals of noisy information about project payoffs in a multi-period setup nor interim cash payoffs contingent on such information. Real-world pay arrangements often involve a bonus the payment of a portion of which is deferred, with the ultimate payment received by the employee depending on information about payoffs that arrives well after the bonus decision. A model that includes intermediate information arrivals and payoffs would be more complicated than the one in this paper. We regard it as a subject for future 
research. 


\section{References}

[1] Arya, A. J. Glover, and B. Mittendorf (2007). "Aligning Incentives by Capping Bonuses," Essays in Accounting Theory in Honour of Joel S. Demski, Springer Publishers.

[2] Arnaiz, O. G. V. Salas-Fumas (2008). "Performance Standards and Optimal Incentives," Journal of Accounting and Economics, 45, 139-152.

[3] Basak, S., A. Pavlova, and A. Shapiro. (2007). "Optimal Asset Allocation and Risk Shifting in Money Management," Review of Financial Studies, 20, 1583-1621.

[4] Bolton, P., P., H. Mehran, and J. Shapiro. (2011) "Executive Compensation and Risk Taking," FRB of New York Staff Report No. 456.

[5] Carpenter, J. (2000). "Does Option Compensation Increase Managerial Risk Appetite?" Journal of Finance 55, 2311-2331.

[6] Clementi, G. L., T. F. Cooley, M. Richardson, and I. Walter. (2009) "Rethinking Compensation in Financial Firms," Restoring financial stability: How to repair a failed system, 197-214.

[7] Davidson, R, and J. Duclos.(2006). "Testing for Restricted Stochastic Dominance," McGill University Working Paper.

[8] DeMarzo, P. M., D. Livdan, and A. Tchistyi. (2011). "Risking Other Peoples Money: Gambling, Limited Liability, and Optimal Incentives," University of California at Berkeley Working Paper.

[9] DeYoung, R., E. Y. Peng, and M. Yan. (2013). "Executive Compensation and Business Policy Choices at U.S. Commercial Banks," Journal of Financial and Quantitative Analysis, 1-47. 
[10] Diamond, P. (1998). "Managerial Incentives: On the Near Linearity of Optimal Compensation," Journal of Political Economy, 106, 931-957.

[11] Doepke, M. and R. M. Townsend. (2006). "Dynamic Mechanism Design with Hidden Income and Hidden Auctions," Journal of Economic Theory 126, 235-285.

[12] Edmans, A. and X. Gabaix. (2008). "Tractability and Detail-Neutrality in Incentive Contracting," NYU Working Paper No. FIN-08-019.

[13] Edmans A. and X. Gabaix. (2011). "Tractability in Incentive Contracting," Review of Financial Studies, 24(9), 2865-2894.

[14] Fahlenbrach, R. and R. M. Stulz, (2011). "Bank CEO Incentives and the Credit Crisis," Journal of Financial Economics, 99(1), 11-26.

[15] Gete, P. and P. G. Gomz. (2013). "A Macroprudential Approach to Executive Compensation," Georgetown University Working paper.

[16] He, Z. (2012). "Compensation Contracts with Private Savings," Review of Financial Studies, 25, 1494-1549.

[17] Healy, P. (1985). "The Effect of Bonus Schemes on Accounting Decisions," Journal of Accounting and Economics 7, 85-107.

[18] Hellwig, M. (2010). "Incentive Problems With Unidimensional Hidden Characteristics: A Unified Approach," Econometrica 78:4, 1201-1237.

[19] Hemmer, T., O. Kim, and R. E. Verrecchia. (2000). "Introducing Convexity into Optimal Compensation Contracts," Journal of Accounting and Economics 28, 307327.

[20] Holmstrom, B. (1979). "Moral Hazard and Observability," Bell Journal of Economics $10,74-91$. 
[21] Innes, Robert D. (1990). "Limited Liability and Incentive Contracting with Ex-ante Action Choices," Journal of Economic Theory 52, 45-67.

[22] Jensen, M. (2003). "Paying People to Lie: the Truth about the Budgeting Process," European Financial Management 9, 379-406.

[23] Jensen, M. and W. Meckling. (1976). "Theory of the Firm: Managerial Behavior, Agency Costs and Ownership Structure," Journal of Financial Economics 3, 305-360.

[24] John, T. and K. John. (1993). "Top-Management Compensation and Capital Structure," Journal of Finance 48, 949-974.

[25] Kadan O. and J. M. Swinkels (2008). "Stocks or Options? Moral Hazard, Firm Viability, and the Design of Compensation Contracts," Review of Financial Studies, 21, $452-481$.

[26] Kashyap, A. R. Rajan, and J. Stein. (2008) "Rethinking Capital Regulation." Federal Reserve Bank of Kansas City Symposium at Jackson Hole.

[27] Marshall, D., and Prescott, E. S. (2001). "Bank Capital Regulation With and Without State Contingent Penalties," Carnegie Rochester Series on Public Policy 54:1, 139-184.

[28] Morck, R., A. Shleiferb, and R. W. Vishny (1988). "Management Ownership and Market Valuation: An Empirical Analysis," Journal of Financial Economics 20, 293315.

[29] Murphy, K. J. (2000). "Performance Standards in Incentive Contracts," Journal of Accounting and Economics 30, 245-278.

[30] Palomino, F. and A. Prat. (2003). "Risk Taking and Optimal Contracts for Money Managers," Rand Journal of Economics, 34, 113-137. 
[31] Phelan, C. (2009). "A Simple Model of Bank Employee Compensation," University of Minnesota and Federal Reserve Bank of Minnesota Working Paper.

[32] Rajan, R. G. (2005) "Has Financial Development Made the World Riskier?" National Bureau of economic Research No. w11728.

[33] Ross, S. (2004). "Compensation, Incentives, and the Duality of Risk Aversion and Riskiness," Journal of Finance 59, 207-225.

[34] Shue, K., and Townsend, R. (2013). "Swinging for the Fences: Executive Reactions to Quasi Random-Option Grants," Chicago Booth Research Paper 13-03.

[35] Smith, C. W. and R. M. Stulz (1985). "The Determinants of Firms' Hedging Policies," Journal of Financial and Quantitative Analysis 20, 391-405. 


\section{Appendix}

\section{A A binary example}

In this section, we use a binary example to convey intuition about drivers in the continuousstate analysis.

\section{A.1 No project choices}

Consider an ordinary risk project, indexed by $o$. There are two possible outcomes, $y_{L}$ and $y_{H}$, where $y_{L}<y_{H}$. Project outcome is influenced by the effort level $(e)$ of the manager, which can be high, $h$, and low, $\ell$. Exerting high effort imposes a cost $c>0$ on the manager. Let $\pi_{e}^{o} \in(0,1)$ be the probability that $y_{H}$ occurs. Assume that $\pi_{h}^{o}>\pi_{\ell}^{o}$. The effort is not observable to the principal, and the principal designs a reward scheme that is a function of the outcome. Let $w_{s}$ be the reward when $y_{s}$ occurs, where $s \in\{L, H\}$.

The manager and the principal are both risk neutral, and the manager has an outside option that provides $\bar{U}$. Assuming that $y_{H}$ is sufficiently large compared to $y_{L}$, the principal wants to induce the manager to put forth effort.

There are two additional constraints for the reward scheme. One is that the reward has to be monotonically increasing in output. As we will see, this constraint is not binding in this setting. The second is that there is a minimum non-negative reward $\underline{w}$ for $w_{s}$.

The principal solves the following optimal contract problem:

$$
\min _{w_{H}, w_{L}}\left(1-\pi_{h}^{o}\right) w_{L}+\pi_{h}^{o} w_{H}
$$

subject to

$$
\begin{gathered}
w_{H} \geq w_{L}, \\
w_{L} \geq \underline{w}, \\
w_{H} \geq \underline{w},
\end{gathered}
$$




$$
\left(1-\pi_{h}^{o}\right) w_{L}+\pi_{h}^{o} w_{H}-c \geq \bar{U},
$$

and

$$
\left(1-\pi_{h}^{o}\right) w_{L}+\pi_{h}^{o} w_{H}-c \geq\left(1-\pi_{\ell}^{o}\right) w_{L}+\pi_{\ell}^{o} w_{H} .
$$

(IC) implies that $w_{H}>w_{L}$, which implies that the first and the third constraints are not binding. Which of the rest of the three are binding depends on the parametric configurations. There are two different cases.

Figure 11: Without project choices

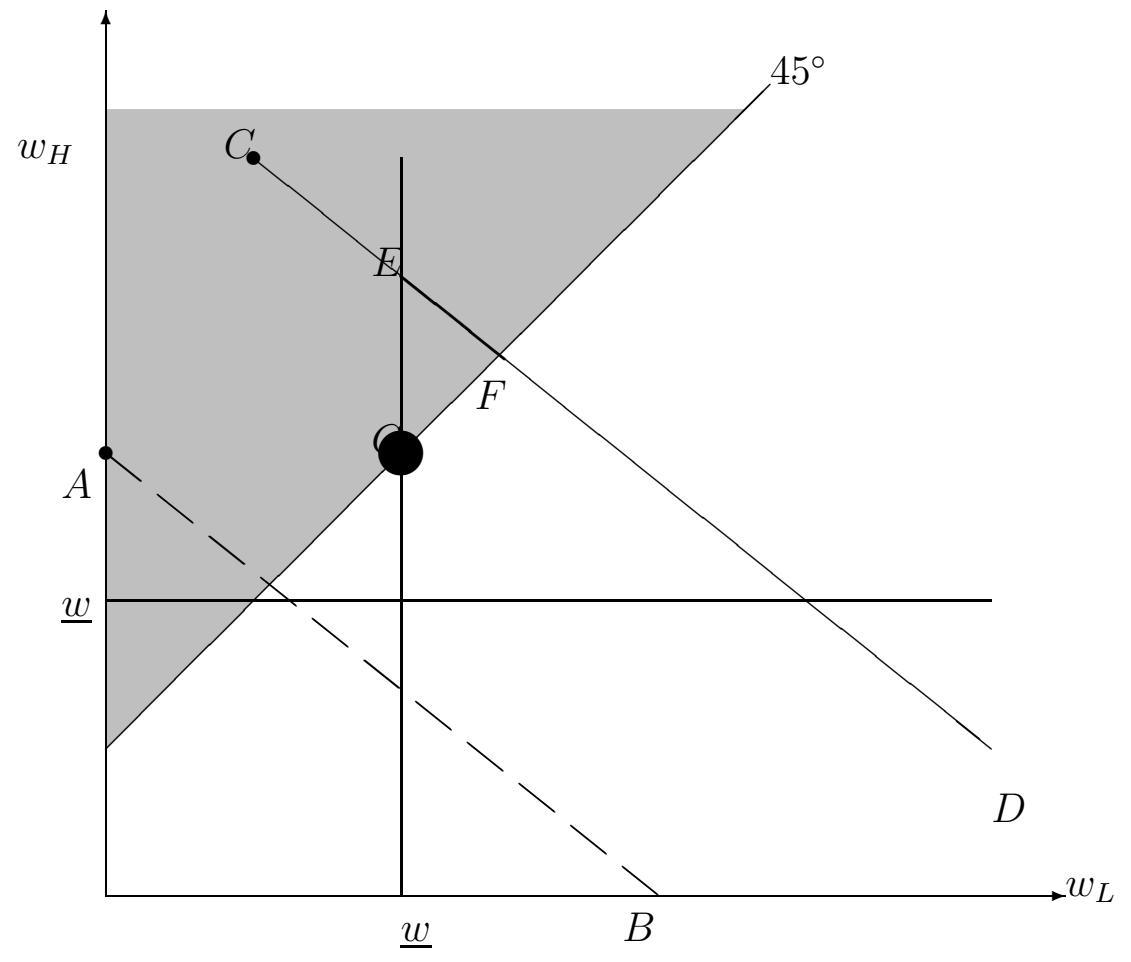

Case $1\left(\underline{w}+\pi_{\ell}^{o} c /\left(\pi_{h}^{o}-\pi_{\ell}^{o}\right) \geq \bar{U}\right)$ :

In this case, $(P C)$ is not binding. The optimal solution is determined by binding $(M 1)$ and $(I C)$ :

$$
w_{L}=\underline{w}
$$


and

$$
w_{H}=\underline{w}+\frac{c}{\pi_{h}^{o}-\pi_{\ell}^{o}} .
$$

The manager's expected payoff is $\underline{w}+\pi_{\ell}^{o} c /\left(\pi_{h}^{o}-\pi_{\ell}^{o}\right)$.

Case $2\left(\underline{w}+\pi_{\ell}^{o} c /\left(\pi_{h}^{o}-\pi_{\ell}^{o}\right)<\bar{U}\right)$ :

In this case, $(P C)$ is binding and any combination of $w_{L}$ and $w_{H}$ that satisfies $(P C)$ with equality, and $(M 1)$ and $(I C)$ with inequality is an optimal solution. The manager's expected payoff is $\bar{U}$.

As shown in Figure 11, the shaded area above the $45^{\circ}$ line $G F$ represents the incentive compatible region defined by $(I C)$. (M1) requires that the solution be above (or on) the horizontal line at $\underline{w}$ and on the right of (or on) the vertical line at $\underline{w} .(P C)$ is represented by the line $A B$ if $(M 1)$ is tighter than $(P C)$ and denoted by the line $C D$ otherwise. Line $A B$ and $C D$ share the same slope as the principal's indifference curve, closer to the origin being better (i.e. a lower objective function value). In Case 1, the point $G$ denotes the optimal solution. In Case 2, any point on the segment EF can be one optimal solution to the principal's problem.

\section{A.2 Project choices}

Now suppose that there is a tail risk project that the manager can choose, in addition to the ordinary project. The tail risk project involves a possibility of having a disaster outcome, $y_{d}<y_{L}$, with the probability $(1-p) \in(0,1)$. Let $w_{d}$ be the wage payment if $y_{d}$ occurs. The probability of $y_{H}$ outcome is $p \pi_{e}^{t}$ when the manager makes an effort $e$, where $\pi_{e}^{t} \in(0,1)$. Assume that the ordinary project is a better project in the sense that it yields a higher expected outcome than the tail risk project. That is,

$$
(1-p) y_{d}+p\left(1-\pi_{h}^{t}\right) y_{L}+p \pi_{h}^{t} y_{H}<\left(1-\pi_{h}^{o}\right) y_{L}+\pi_{h}^{o} y_{H}
$$

holds. In addition, assume that $p\left(\pi_{h}^{t}-\pi_{\ell}^{t}\right) \geq \pi_{h}^{o}-\pi_{\ell}^{o}$, so that the manager has an incentive to make an effort with the tail risk project if the ordinary risk project's $(I C)$ is satisfied. 
Consider Case 1 in the previous section. (Case 2 is less interesting.) Under the optimal payoff in the previous section (and $w_{d}=\underline{w}$ from the monotonicity constraint), the manager's payoff is

$$
(1-p) \underline{w}+p\left(1-\pi_{h}^{t}\right) \underline{w}+p \pi_{h}^{t}\left(\underline{w}+\frac{c}{\pi_{h}^{o}-\pi_{\ell}^{o}}\right)-c=\underline{w}+\frac{p \pi_{h}^{t}-\pi_{h}^{o}+\pi_{\ell}^{o}}{\pi_{h}^{o}-\pi_{\ell}^{o}} c .
$$

This is larger than the manager's payoff when choosing the ordinary risk project if and only if $p \pi_{h}^{t} \geq \pi_{h}^{o}$. (Only the $H$ event matters for the manager's incentive.) Then, when the principal cannot dictate the project choice, the manager will choose the tail risk project.

Figure 12: With project choices

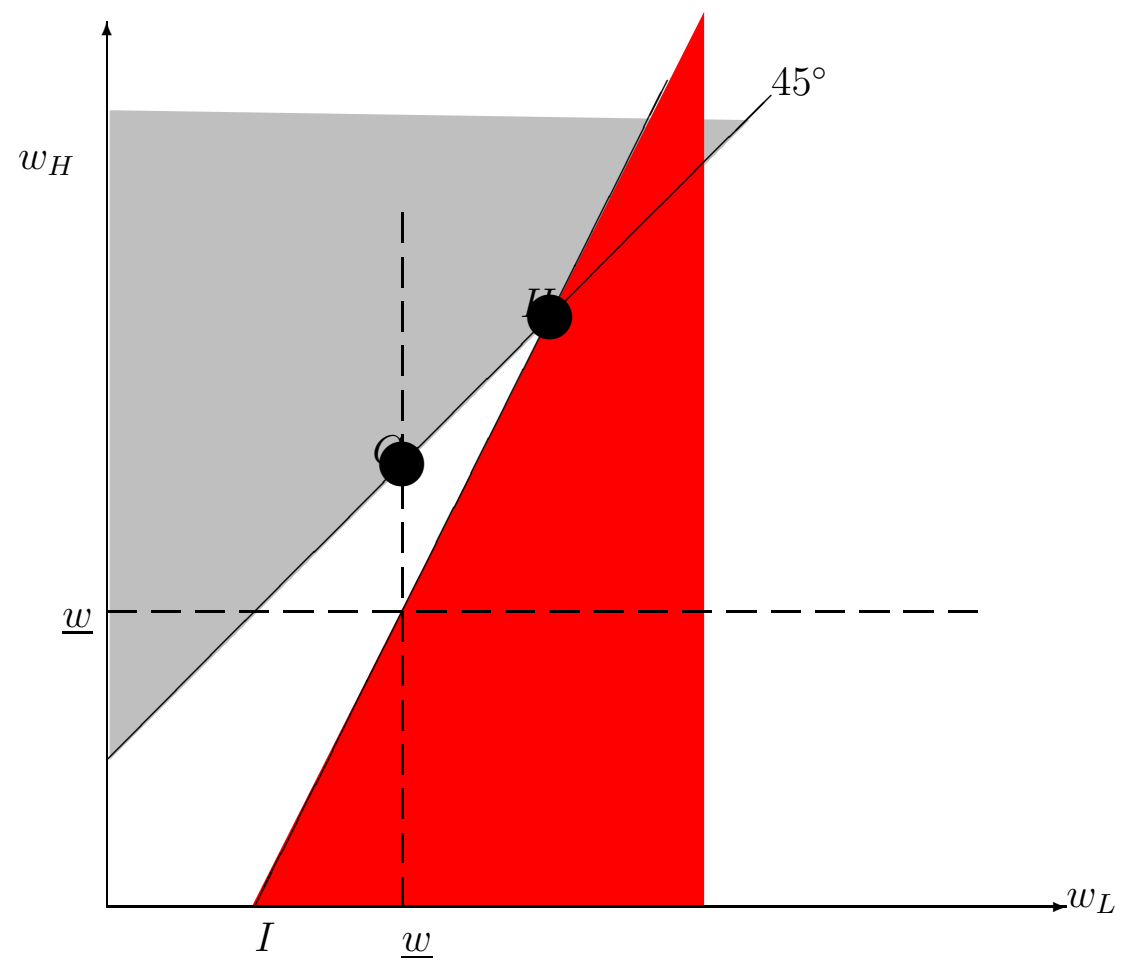

Taking this into consideration, the investor has to design the reward with an additional constraint:

$$
(1-p) w_{d}+p\left(1-\pi_{h}^{t}\right) w_{L}+p \pi_{h}^{t} w_{H} \leq\left(1-\pi_{h}^{o}\right) w_{L}+\pi_{h}^{o} w_{H}
$$


When $\bar{U}$ is sufficiently low so that the participation constraint is not binding, clearly $w_{d}=\underline{w}$ has to be satisfied. Note that when $p \pi_{h}^{t} \geq \pi_{h}^{o}$ is satisfied, $p\left(1-\pi_{h}^{t}\right)<\left(1-\pi_{h}^{o}\right)$. This implies that $y_{L}$ is relatively likely to happen with the ordinary risk project. The constraint $(P R)$ can be rewritten as

$$
w_{H} \leq \frac{1-p+p \pi_{h}^{t}-\pi_{h}^{o}}{p \pi_{h}^{t}-\pi_{h}^{o}} w_{L}-\frac{(1-p) \underline{w}}{p \pi_{h}^{t}-\pi_{h}^{o}} .
$$

Note that this equation holds with equality when $\left(w_{L}, w_{H}\right)=(\underline{w}, \underline{w})$ and the coefficient on $w_{L}$ is larger than 1 . It can be shown that at the optimal solution, $(I C)$ and $(P R)$ are binding. ${ }^{23}$ The optimal reward satisfies $w_{L}>\underline{w}$ and $w_{H}=w_{L}+c /\left(\pi_{h}^{o}-\pi_{\ell}^{o}\right)$.

Compared to the previous section, the reward shifts up $\left(w_{L}, w_{H}\right)$ in a parallel manner. The intuition is that since $y_{L}$ is more likely to happen with the ordinary risk project, $y_{L}$ event has to be rewarded so that the manager will choose the ordinary project. The fact that $y_{L}$ became important is a result of having only two possible outcomes. In the continuous model presented in the body of the paper, our key result is not an artifact of the simple contract space. If there are more than two possible outcomes, it is plausible that there is an event $i$ that is not $L$ and is more likely to happen with the ordinary risk project, so that the tail risk project looks better for the manager when the project choice is ignored in compensation design. Whichever event is more likely to happen with the ordinary project will be rewarded when projects are chosen. Introducing project choices into a standard moral hazard problem changes the optimal structure of compensation. A compensation arrangement that is optimal without tail risk choices may actually induce the choice of tail risk if it is available.

In Figure 12, the red area below the line $I H$ represents the risk-taking incentive compatible region defined by $(P R)$. As noted in Figure 11, the grey area above the line $G H$ represents the effort-making incentive compatible region defined by $(I C)$. Thus, the lowest point $(H)$ at which the red area overlaps with the grey area is the optimal solution

\footnotetext{
${ }^{23}$ If either of $(I C)$ and $(P R)$ is not binding under the optimal contract, a reduction of $w_{L}$ or $w_{H}$ will still satisfy the incentive constraints and decrease the objective function value — it causes a contradiction.
} 


\begin{tabular}{|r|r|r|r|r|r|r|r|r|r|r|}
\hline $\mathrm{E}[\mathrm{w} \mid 0, \mathrm{~h}]$ & 72 & 74 & 76 & 78 & 80 & 82 & 84 & 86 & 88 & 90 \\
\hline 12 & 3.852 & 3.852 & 3.852 & 3.852 & 3.852 & 3.852 & 5.000 & 6.400 & 7.545 & 8.500 \\
\hline 14 & 3.852 & 3.852 & 3.852 & 3.852 & 3.852 & 3.852 & 5.500 & 7.000 & 8.200 & 9.182 \\
\hline 16 & 3.852 & 3.852 & 3.852 & 3.852 & 3.852 & 3.912 & 6.143 & 7.750 & 9.000 & 10.000 \\
\hline 18 & 3.852 & 3.852 & 3.852 & 3.852 & 3.852 & 4.381 & 7.000 & 8.714 & 10.000 & 11.000 \\
\hline 20 & 3.852 & 3.852 & 3.852 & 3.852 & 3.852 & 5.167 & 8.200 & 10.000 & 11.286 & 12.250 \\
\hline 22 & 3.852 & 3.852 & 3.852 & 3.852 & 3.852 & 6.594 & 10.000 & 11.800 & 13.000 & 13.857 \\
\hline 24 & 3.852 & 3.852 & 3.852 & 3.852 & 3.852 & 9.667 & 12.898 & 14.489 & 15.373 & 15.958 \\
\hline 26 & 3.852 & 3.852 & 3.852 & 3.852 & 3.852 & 13.000 & 15.933 & 17.843 & 18.247 & 18.776 \\
\hline 28 & 3.852 & 3.852 & 3.852 & 3.852 & 13.000 & 16.000 & 19.877 & 21.870 & 22.002 & 22.441 \\
\hline 30 & 3.852 & 3.852 & 3.852 & 3.852 & 16.000 & 22.533 & 24.876 & 25.580 & 25.408 & 25.750 \\
\hline
\end{tabular}

Figure 13: Expected wage payment

when there is a project choice. The point $H$ being higher than the point $G$ indicates that incentive alignment becomes more expensive when there is risk choice.

\section{B Comparative Statics}

This part of the Appendix presents details of comparative statics that are summarized in the text. Figure 13 displays how the manager's expected pay varies with the support of the tail-risk project. Rows vary the lower bound of the continuous part of the tail-risk payoff distribution and columns vary the upper bound. As we move from the upper left corner towards the lower right corner, the tail-risk project becomes more profitable and has an expected value closer to the ordinary-risk project keeping the disaster state and probability fixed. Therefore, it becomes increasingly expensive to deter tail risk.

Figure 14 displays how the equilibrium piece rate $\theta$ varies with the support of the tailrisk project. For the same reason that the optimal floor and cap depend crucially on the 


\begin{tabular}{|l|r|r|r|r|r|r|r|r|r|r|}
\hline$\theta$ & 72 & 74 & 76 & 78 & 80 & 82 & 84 & 86 & 88 & 90 \\
\hline 12 & 1.000 & 1.000 & 1.000 & 1.000 & 1.000 & 1.000 & 0.860 & 0.667 & 0.668 & 0.546 \\
\hline 14 & 1.000 & 1.000 & 1.000 & 1.000 & 1.000 & 1.000 & 0.788 & 0.700 & 0.575 & 0.523 \\
\hline 16 & 1.000 & 1.000 & 1.000 & 1.000 & 1.000 & 1.000 & 0.731 & 0.550 & 0.513 & 0.541 \\
\hline 18 & 1.000 & 1.000 & 1.000 & 1.000 & 1.000 & 1.000 & 0.626 & 0.530 & 0.552 & 0.557 \\
\hline 20 & 1.000 & 1.000 & 1.000 & 1.000 & 1.000 & 0.945 & 0.596 & 0.565 & 0.479 & 0.551 \\
\hline 22 & 1.000 & 1.000 & 1.000 & 1.000 & 1.000 & 0.720 & 0.473 & 0.626 & 0.609 & 0.636 \\
\hline 24 & 1.000 & 1.000 & 1.000 & 1.000 & 1.000 & 0.557 & 0.395 & 0.587 & 0.700 & 0.800 \\
\hline 26 & 1.000 & 1.000 & 1.000 & 1.000 & 1.000 & 0.333 & 0.336 & 0.897 & 1.000 & 1.000 \\
\hline 28 & 1.000 & 1.000 & 1.000 & 1.000 & 0.333 & 0.333 & 0.414 & 0.862 & 0.999 & 1.000 \\
\hline 30 & 1.000 & 1.000 & 1.000 & 1.000 & 0.333 & 0.491 & 0.638 & 0.846 & 1.000 & 1.000 \\
\hline
\end{tabular}

Figure 14: Equilibrium incentives $\theta$

relationship between the tail-risk payoff and ordinary-risk payoff distributions, the impact of small changes in the tail-risk payoff support on $\theta$ varies widely.

Figure 15 and 16 show how the expected wage varies with the cost of effort $c$ and the value of effort $\kappa$. As the cost of effort increases, the equilibrium piece rate $(\theta)$ increases, the incentive region enlarges (the floor and cap diverge), and the expected payment to the manager rises. As effort becomes more valuable in increasing payoffs, it is less expensive to induce effort, and consequently both the equilibrium piece rate and incentive region shrink.

Figure 17 shows how the expected payment to the manager varies with the disaster probability $(1-p)$. As $p$ increases, the probability of disaster decreases, and the expected value of the tail-risk project increases. It becomes more expensive to disincentivize it, and thus the expected wage increases. 


\begin{tabular}{lllll}
\hline $\mathrm{E}[\mathrm{w} \mid \mathrm{o}, \mathrm{h}]$ & COST & $\theta$ & $y_{f}$ & $y_{c}$ \\
\hline 2.2222 & 0.333 & 0.351 & 51.454 & 72.545 \\
4.4444 & 0.667 & 0.555 & 48.654 & 75.345 \\
6.6666 & 1.000 & 0.788 & 47.916 & 76.083 \\
8.8888 & 1.333 & 0.903 & 45.598 & 78.401 \\
11.234 & 1.667 & 0.999 & 43.283 & 80.465 \\
14.352 & 2.000 & 0.999 & 38.499 & 81.234 \\
19.333 & 2.333 & 0.999 & 31.833 & 80.849 \\
25.055 & 2.667 & 0.999 & 25.166 & 80.832 \\
32.999 & 3.000 & 1.000 & 17.000 & 81.106 \\
\hline
\end{tabular}

Figure 15: Comparative statics around effort cost

\begin{tabular}{lllll}
\hline $\mathrm{E}[\mathrm{w} \mid \mathrm{o}, \mathrm{h}]$ & $\mathrm{k}$ & $\theta$ & $y_{f}$ & $y_{c}$ \\
\hline 17.37 & 1.333 & 1.000 & 34.333 & 81.125 \\
11.80 & 1.667 & 0.996 & 42.262 & 78.406 \\
10.00 & 2.000 & 0.905 & 43.591 & 79.237 \\
8.571 & 2.333 & 0.845 & 45.105 & 78.894 \\
7.500 & 2.667 & 0.801 & 46.394 & 77.605 \\
6.666 & 3.000 & 0.786 & 47.866 & 76.133 \\
6.000 & 3.333 & 0.679 & 47.291 & 76.708 \\
5.454 & 3.667 & 0.686 & 48.756 & 75.243 \\
5.000 & 4.000 & 0.621 & 48.598 & 75.401 \\
\hline
\end{tabular}

Figure 16: Comparative statics around value of effort 


\begin{tabular}{llllll}
\hline $\mathrm{E}[\mathrm{w} \mid \mathrm{o}, \mathrm{h}]$ & $\mathrm{P}$ & $\theta$ & $y_{f}$ & $y_{c}$ & Intersection Point \\
\hline 7.017 & 0.905 & 0.752 & 46.254 & 75.639 & 60.947 \\
7.407 & 0.910 & 0.699 & 44.075 & 75.480 & 59.777 \\
7.843 & 0.915 & 0.657 & 41.859 & 75.081 & 58.470 \\
8.333 & 0.920 & 0.629 & 39.738 & 74.261 & 57.000 \\
8.888 & 0.925 & 0.640 & 38.445 & 72.220 & 55.333 \\
9.523 & 0.930 & 0.561 & 34.277 & 72.579 & 53.428 \\
10.25 & 0.935 & 0.552 & 31.871 & 70.589 & 51.230 \\
11.05 & 0.940 & 0.425 & 23.905 & 74.355 & 48.666 \\
11.97 & 0.945 & 0.406 & 20.216 & 73.490 & 45.636 \\
13.19 & 0.950 & 0.435 & 18.638 & 68.841 & 42.000 \\
\hline
\end{tabular}

Figure 17: Comparative statics around disaster probability

\section{Proofs}

Proof of Lemma 1: Because the expected wage is increasing in $\theta$, if $\underline{w}$ is relatively small and the inherent kink in stock compensation is no greater than the lower bound of the price distribution, i.e. $\underline{w} / \theta \leq \underline{y}$, incentive compatibility on effort must be binding: $\theta^{*}=\frac{c}{\kappa}$. Otherwise, a reduction of $\theta$ can reduce the principal's cost of implementing effort and thus will cause a contradiction. If $\underline{w} \leq \frac{c \underline{y}}{\kappa}$, the condition above is satisfied, i.e. $\theta^{*} \underline{y} \geq \underline{w}$. The expected wage payment in this case is $E[w \mid h]=\theta^{*} E\left[y_{o} \mid h\right]=c \mu_{o} / \kappa$.

Proof of Lemma 2: Following Equation (1), we derive $E\left[y_{i} \mid y_{i} \geq y^{*}, h\right]$, where $i \in\{o, t\}$, 
in the following. Notation for conditionality on high effort $(h)$ is suppressed for brevity.

$$
\begin{array}{ccc} 
& E\left[y_{i} \mid y_{i} \geq y^{*}\right] \\
= & y^{*} F\left(y^{*}\right)+\int_{y^{*}}^{\overline{y_{i}}} y f_{i}\left(y_{i}\right) d y \\
= & \int_{\underline{y_{i}}}^{y^{*}} y^{*} f_{i}\left(y_{i}\right) d y+\int_{y^{*}}^{\overline{y_{i}}} y f_{i}\left(y_{i}\right) d y \\
> & \int_{\underline{y_{i}}}^{y^{*}} y f_{i}(y) d y+\int_{y^{*}}^{\overline{y_{i}}} y f_{i}\left(y_{i}\right) d y \\
= & \int_{y_{i}}^{\overline{y_{i}}} y f_{i}(y) d y \\
= & E\left[y_{i}\right]
\end{array}
$$

From Equation (1), we have

$$
E\left[y_{i} \mid y_{i} \geq y^{*}\right]=\overline{y_{i}}-\int_{y^{*}}^{\overline{y_{i}}} F_{i}\left(y_{i}\right) d y, \quad \forall i \in\{o, t\} .
$$

which is increasing in $y^{*}$.

Proof of Lemma 3: Let $\Delta$ denote the difference in expected payoffs above the exercise price, that is, $\Delta \equiv E\left[y_{o} \mid y_{o} \geq y^{*}, h\right]-E\left[y_{t} \mid y_{t} \geq y^{*}, h\right]$. Thus, the option compensation differential is represented by $\theta \Delta$. Following Proposition 2, we have $E\left[y_{i} \mid y_{i} \geq y^{*}\right]=y^{*} F\left(y^{*}\right)+$ $\int_{y^{*}}^{\overline{y_{i}}} y f_{i}\left(y_{i}\right) d y$. We re-write $\Delta$ using Equation(1) as $\Delta=\bar{y}_{o}-\bar{y}_{t}+\int_{y^{*}}^{\bar{y}_{t}} F_{t}(y) d y-\int_{y^{*}}^{\bar{y}_{o}} F_{o}(y) d y$. The derivative of $\Delta$ with respect to $y^{*}$ is $\frac{d \Delta}{d y^{*}}=F_{o}\left(y^{*}\right)-F_{t}\left(y^{*}\right) \geq 0$. Thus, $\Delta$ is weakly increasing in $y^{*}$. Suppose that $\left(I C_{R 1}\right)$ is not binding. A reduction of $\underline{y}^{*}$ will still satisfy the constraint on risk choice and induce a reduction of $\theta^{*}$ and hence the value of the objective function - therefore, it causes a contradiction.

Proof of Lemma 4:Incentive compatibility on the effort decision $\left(I C_{e}\right)$ requires

$$
\theta \geq \frac{c}{\int_{y^{*}}^{\overline{y_{o}}} G_{o}(y) d y-\int_{y^{*}}^{\overline{y_{o}}-\kappa} G_{o}(y+\kappa) d y}=\theta_{1},
$$

and incentive compatibility on the risk choice $\left(I C_{R 2}\right)$ requires

$$
\theta \geq \frac{c}{\left.\int_{y^{*}}^{\overline{y_{o}}} G_{o}(y) d y-\int_{y^{*}}^{\overline{y_{t}}-\kappa} G_{t}(y+\kappa)\right] d y}=\theta_{2} .
$$


Thus, $\theta^{*}=\max \left\{\theta_{1}, \theta_{2}\right\}$. $\left(I C_{R 1}\right)$ implies that $\int_{y^{*}}^{\overline{y_{o}}} G_{o}(y) d y>\int_{y^{*}}^{\overline{y_{t}}} G_{t}(y+\kappa) d y$, which is equivalent to $\int_{y^{*}-\kappa}^{\overline{y_{o}}-\kappa} G_{o}(y+\kappa) d y>\int_{y^{*}-\kappa}^{\overline{y_{t}}-\kappa} G_{t}(y+\kappa) d y$. We define $\Delta^{\prime} \equiv E\left[y_{o} \mid y_{o} \geq y^{*}, l\right]-$ $E\left[y_{t} \mid y_{t} \geq y^{*}, l\right]$, which can be rewritten as

$$
\begin{aligned}
\Delta^{\prime} & =\int_{y^{*}-\kappa}^{\overline{y_{o}}-\kappa} G_{o}(y+\kappa) d y-\int_{y^{*}-\kappa}^{\overline{y_{t}}-\kappa} G_{t}(y+\kappa) d y \\
& =\overline{y_{o}}-\overline{y_{t}}-\int_{y^{*}-\kappa}^{\overline{y_{o}}-\kappa} F_{o}(y+\kappa) d y+\int_{y^{*}-\kappa}^{\overline{y_{t}}-\kappa} F_{t}(y+\kappa) d y .
\end{aligned}
$$

Taking derivative of $\Delta^{\prime}$ with respect to $y *$ is $\frac{d \Delta^{\prime}}{d y^{*}}=F_{o}\left(y^{*}\right)-F_{t}\left(y^{*}\right) \geq 0$. Therefore, since $\int_{y^{*}-\kappa}^{\overline{y_{o}}-\kappa} G_{o}(y+\kappa) d y>\int_{y^{*}-\kappa}^{\overline{y_{t}}-\kappa} G_{t}(y+\kappa) d y, \int_{y^{*}}^{\overline{y_{o}}-\kappa} G_{o}(y+\kappa) d y>\int_{y^{*}}^{\overline{y_{t}}-\kappa} G_{t}(y+\kappa) d y$ also holds. Now as $\theta_{1}>\theta_{2}$, in the equilibrium we have

$$
\begin{aligned}
\theta & =\theta_{1}=\frac{c}{\int_{y^{*}}^{\overline{y_{o}}} G_{o}(y) d y-\int_{y^{*}}^{\overline{y_{o}}-\kappa} G_{o}(y+\kappa) d y} \\
& =\frac{c}{\overline{y_{o}}-\int_{y^{*}}^{\overline{y_{o}}} F_{o}(y) d y-\left(\overline{y_{o}}-\kappa\right)+\int_{y^{*}}^{\overline{y_{o}}-\kappa} F_{o}(y+\kappa) d y} \\
& =\frac{c}{\kappa+\int_{y^{*}+\kappa}^{\overline{y_{o}}} F_{o}(y) d y-\int_{y^{*}}^{\overline{y_{o}}} F_{o}(y) d y} \\
& =\frac{c}{\kappa-\int_{y^{*}}^{y^{*}+\kappa} F_{o}(y) d y},
\end{aligned}
$$

which is strictly increasing in $y^{*}$.

Proof of Proposition 3: When collar options are used, we have $w(y)=\left(\underline{w}-\theta y^{f}\right)+$ $\theta \min \left\{\max \left\{y, y^{f}\right\}, y^{c}\right\}$. For brevity, we only derive the condition for $\left(I C_{R 1}\right)$ to be satisfied below. Conditions analogous to those in Section 4.1 hold for $\left(I C_{R 2}\right)$ and $\left(I C_{e}\right)$. $\left(I C_{R 1}\right)$ requires $E\left[w\left(y_{o}\right) \mid h\right] \geq E\left[w\left(y_{t}\right) \mid h\right]$, which becomes equivalent to $E\left[y_{o} \mid y^{f} \leq y_{o} \leq y^{c}, h\right] \geq$ $E\left[y_{t} \mid y^{f} \leq y_{t} \leq y^{c}, h\right]$. We derive $E\left[y_{i} \mid y^{f} \leq y_{i} \leq y^{c}, h\right]$, where $i \in\{o, t\}$, in the following. 
Notation conditioning on high effort $(h)$ is suppressed for brevity.

$$
\begin{array}{cc}
E\left[y_{i} \mid y^{f} \leq y_{i} \leq y^{c}\right] & \\
= & y^{f} F_{i}\left(y^{f}\right)+\int_{y^{f}}^{y^{f}} y f_{i}(y) d y+y^{c}\left[1-F_{i}\left(y^{c}\right)\right] \\
= & y^{f} F_{i}\left(y^{f}\right)+\left[y F_{i}(y)\right]_{y^{f}}^{y^{c}}-\int_{y^{f}}^{y^{c}} F_{i}(y) d y+y^{c}\left[1-F_{i}\left(y^{c}\right)\right] \\
= & y^{f} F_{i}\left(y^{f}\right)+y^{c} F_{i}\left(y^{c}\right)-y^{f} F_{i}\left(y^{f}\right)-\int_{y^{f}}^{y^{c}} F_{i}(y) d y+y^{c}-y^{c} F_{i}\left(y^{c}\right) \\
= & y^{c}-\int_{y^{f}}^{y^{c}} F_{i}(y) d y \cdot \square
\end{array}
$$

Proof of Proposition 4: Suppose that collars cannot deter tail risk, then we have

$$
\int_{y^{f}}^{y^{c}} F_{t}(y) d y<\int_{y^{f}}^{y^{c}} F_{o}(y) d y, \quad \forall\left\{y^{f}, y^{c}\right\}
$$

If $\overline{y_{t}}<\overline{y_{o}}$, setting $y^{f}=\overline{y_{t}}, y^{c}=\overline{y_{o}}$ in (7) leads to $\int_{\overline{y_{t}}}^{\overline{y_{o}}} F_{t}(y) d y<\int_{\overline{y_{t}}}^{\overline{y_{o}}} F_{o}(y) d y$. It is straightforward to see that the left-hand side equals to $\overline{y_{o}}-\overline{y_{t}}$, while the right-hand side is apparently less than $\overline{y_{o}}-\overline{y_{t}}$ since $F(y)<1, \forall y \in\left[\overline{y_{t}}, \overline{y_{0}}\right)$. This causes a contradiction.

If $\underline{y_{t}}<\underline{y_{o}}$, setting $y^{f}=\underline{y_{t}}, y^{c}=\underline{y_{o}}$ in (7) leads to $\int_{\underline{y_{t}}}^{\underline{y_{o}}} F_{t}(y) d y<\int_{\underline{y_{t}}}^{\underline{y_{o}}} F_{o}(y) d y$. It is straightforward to see that the left-hand side is positive, while the right-hand side equals to zero. This causes a contradiction.

Proof of Proposition 5: With monitoring, managerial compensation conditional on taking ordinary risk under the "status quo" stock compensation illustrated in Lemma 1 is

$$
\begin{gathered}
E\left[w\left(y_{o}\right) \mid h, o\right]=\theta^{*} \mu_{o}=c \mu_{o} / \kappa . \\
E\left[w\left(y_{t}\right) \mid h, t\right]=p_{s} \underline{w}+\left(1-p_{s}\right)\left[(1-p) \underline{w}+c \mu_{t} / \kappa\right] .
\end{gathered}
$$

The manager will choose the ordinary risk project if and only if $E\left[w\left(y_{o}\right) \mid h, o\right] \geq E\left[w\left(y_{t}\right) \mid h, t\right]$, that is,

$$
p_{s} \geq 1-\left(\frac{\frac{c}{\kappa} \mu_{o}-\underline{w}}{\frac{c}{\kappa} \mu_{t}-p \underline{w}}\right)
$$




\section{Proof of Proposition 6:}

$$
\begin{aligned}
& \underline{w}-\theta y^{*}+\theta E\left[y_{o} \mid y_{o} \geq y^{*}\right] \geq p_{s} \underline{w}+\left(1-p_{s}\right)\left[\underline{w}-\theta y^{*}+\theta E\left[y_{t} \mid y_{t} \geq y^{*}\right]\right] \\
& \theta\left[y^{*}+\int_{y^{*}}^{\bar{y}} G_{o}(y) d y\right] \geq p_{s} \theta y^{*}+\left(1-p_{s}\right) \theta\left[y^{*}+\int_{y^{*}}^{\bar{y}} G_{t}(y) d y\right] \\
& \int_{y^{*}}^{\overline{y_{o}}} G_{o}(y) d y \geq\left(1-p_{s}\right) \int_{y^{*}}^{\overline{y_{t}}} G_{t}(y) d y . \square
\end{aligned}
$$

\section{The effect of risk aversion}

It is informative to compare this result with the standard principal-agent result. In the standard principal-agent model, the principal and agent have a conflict of interest over variations in outcomes, and the optimal compensation contract consists of a base wage plus a piece rate. The agent is thus always in the incentive region of the contract: if the agent is risk averse, the principal chooses to reduce the piece rate to minimize the agent's exposure to the variation; if the agent is risk neutral, there is no conflict of interest between the principal and the agent, and a contract with a piece rate of one hundred percent yields the first-best outcome. In the model in this paper, the agent is not averse to variations in income, but is shielded from bad tail outcomes due to the minimum wage constraint. A flat region in the pay function that is unresponsive to low payoff realizations effectively alters the relative value to the manager of project outcomes, and is thus introduced to control for managerial risk taking and align the interests of managers with shareholders.

Our key result can be extended to a risk averse manager. The manager's utility is then represented by $U(e, y)=u[w(y)]-a(e)$, where $u(\cdot)$ is strictly increasing and strictly concave. The condition for options to be an effective means of avoiding tail risk in this case is identical to that if the manager is risk neutral.

Proposition 7 A necessary and sufficient condition under which options can be used to avoid tail risk taking when the manager is risk averse is identical to that when the manager 
is risk neutral:

$$
\int_{y^{*}}^{\overline{y_{o}}} G_{o}(y) d y \geq \int_{y^{*}}^{\overline{y_{t}}} G_{t}(y) d y
$$

Proof: Since $u(\cdot)$ is strictly increasing, $\left(I C_{R 1}\right)$ is reduced to

$$
E\left[w\left(y_{o}\right) \mid y^{*}, h\right] \geq E\left[w\left(y_{t}\right) \mid y^{*}, h\right]
$$

which leads to inequality (2), identical to the condition when the manager is risk neutral. Incentive compatibility requires the manager to exert effort if $\left(I C_{e}\right)$ is met. Since $u(\cdot)$ is strictly concave, the manager is less motivated by compensation changes at different price levels, because higher wealth translates into a lower marginal utility of income. It is thus more costly to motivate a risk-averse manager to exert effort than a risk-neutral manager, that is,

$$
\theta>\frac{c}{\int_{y^{*}}^{\overline{y_{o}}}\left[G_{o}(y)-G_{o}(y+\kappa)\right]} d y .
$$

Analogous to the case of a risk neutral manager, the incentive compatibility constraint on risk choice off the equilibrium path (condition $\left(I C_{R 2}\right)$ ) can be satisfied when $\left(I C_{R 1}\right)$ and $\left(I C_{e}\right)$ are both met. Therefore, inequality (2) remains the necessary and sufficient condition for option compensation to be an optimal motivational tool.

\section{E The condition when distributions are unbounded}

Proposition 8 A necessary and sufficient condition for call options to be optimal when the distributions of payoffs are unbounded is

$$
\int_{y^{*}}^{\infty} G_{o}(y) d y \geq \int_{y^{*}}^{\infty} G_{t}(y) d y,
$$

where $y_{0} \in\{-\infty, \infty\}$ and $y_{t} \in\{-\infty, \infty\}$ are the payoffs generated by the ordinary risk project and tail risk project respectively; $G_{o}(\cdot)=1-F_{o}(\cdot), G_{t}(\cdot)=1-F_{t}(\cdot)$, and $F_{o}(\cdot)$ and $F_{t}(\cdot)$ are the cumulative distribution functions of payoffs associated with the ordinary risk and tail risk projects respectively; $y^{*}$ is the floor specified in the options. 


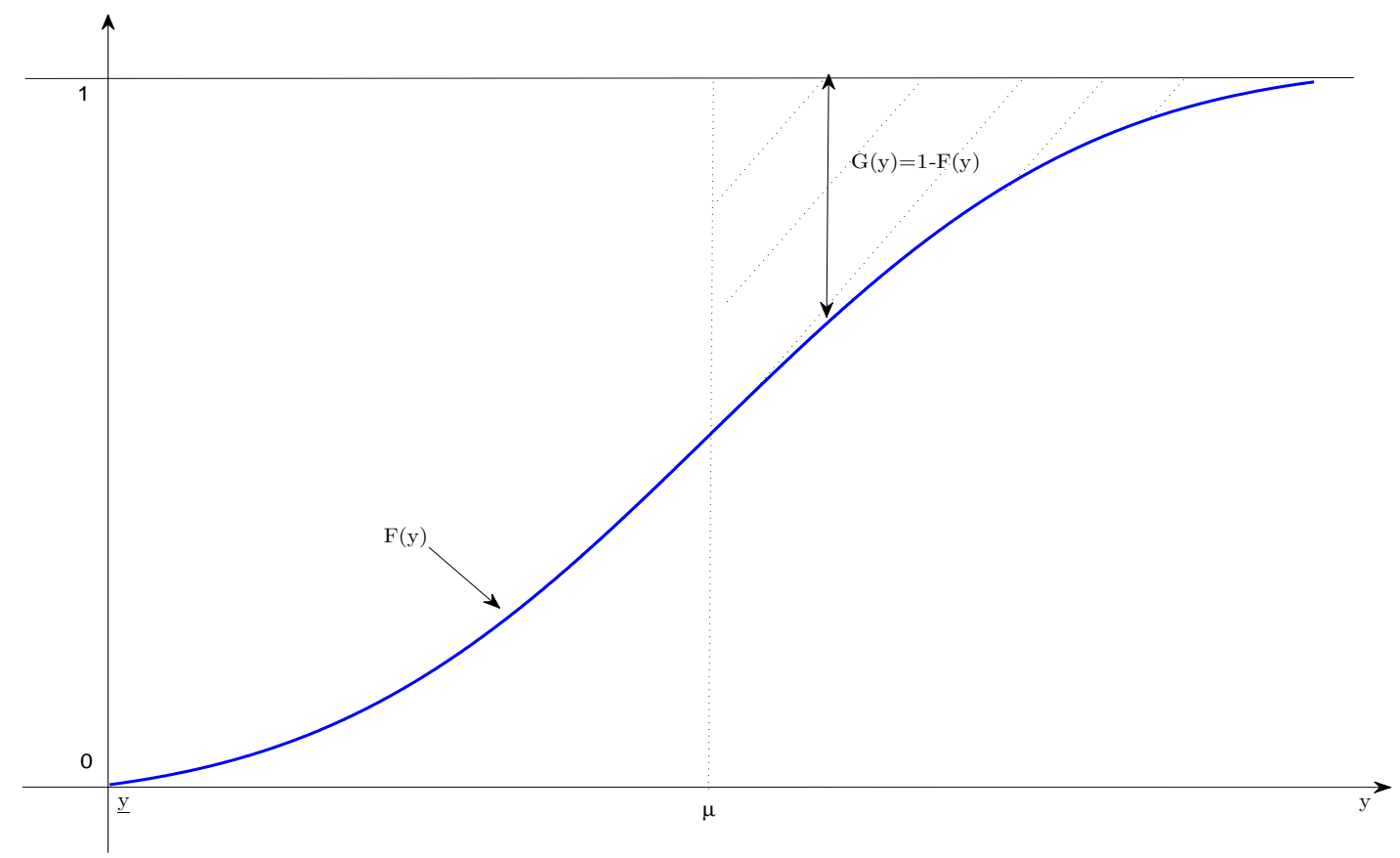

Figure 18: Stocks versus Options (CDF)

Proof: If the payoffs follow an unbounded distribution, following the proof of Proposition 1, $E\left[y \mid y \geq y^{*}\right]=y^{*} F\left(y^{*}\right)+\int_{y^{*}}^{\infty} y f(y) d y=y^{*} F\left(y^{*}\right)+[y F(y)]_{y^{*}}^{\infty}-\int_{y^{*}}^{\infty} F(y) d y$. Let $G(\cdot)=$ $1-F(\cdot)$, and we have

$$
\begin{aligned}
E\left[y \mid y \geq y^{*}\right] & =y^{*} F\left(y^{*}\right)+[y(1-G(y))]_{y^{*}}^{\infty}-\int_{y^{*}}^{\infty}(1-G(y)) d y \\
& =y^{*} F\left(y^{*}\right)+[y]_{y^{*}}^{\infty}-[y G(y)]_{y^{*}}^{\infty}-[y]_{y^{*}}^{\infty}+\int_{y^{*}}^{\infty} G(y) d y \\
& =y^{*} F\left(y^{*}\right)+y^{*} G\left(y^{*}\right)-\lim _{\bar{y} \rightarrow \infty}[\bar{y} G(\bar{y})]+\int_{y^{*}}^{\infty} G(y) d y \\
& =y^{*}\left[1-G\left(y^{*}\right)\right]+y^{*} G\left(y^{*}\right)-0+\int_{y^{*}}^{\infty} G(y) d y \\
& =y^{*}+\int_{y^{*}}^{\infty} G(y) d y .
\end{aligned}
$$

In figure 18, the dashed area represents the the integral specified in Proposition 1. As 
it is an integration from above, it does not directly imply stochastic dominance, which requires a comparison of integrals from below. However, when the distributions of the projects' outcomes are both symmetric (apart from the disaster outcome), this condition is equivalent to saying that the value generated from the tail risk project second-order stochastically dominates that from the ordinary risk project at the high end. 